\title{
Caveolin1 Identifies a Specific Subpopulation of Cerebral Cortex Callosal Projection Neurons (CPN) Including Dual Projecting Cortical Callosal/ Frontal Projection Neurons (CPN/FPN)
}

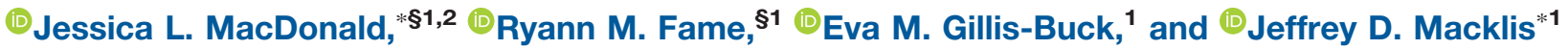

DOI:http://dx.doi.org/10.1523/ENEURO.0234-17.2017

${ }^{1}$ Department of Stem Cell and Regenerative Biology, Center for Brain Science, and Harvard Stem Cell Institute, Harvard University, Cambridge, MA 02138 and ${ }^{2}$ Department of Biology, Syracuse University, Syracuse, NY 13244

\begin{abstract}
The neocortex is composed of many distinct subtypes of neurons that must form precise subtype-specific connections to enable the cortex to perform complex functions. Callosal projection neurons (CPN) are the broad population of commissural neurons that connect the cerebral hemispheres via the corpus callosum (CC). Currently, how the remarkable diversity of CPN subtypes and connectivity is specified, and how they differentiate to form highly precise and specific circuits, are largely unknown. We identify in mouse that the lipid-bound scaffolding domain protein Caveolin 1 (CAV1) is specifically expressed by a unique subpopulation of Layer V CPN that maintain dual ipsilateral frontal projections to premotor cortex. CAV1 is expressed by over $80 \%$ of these dual projecting callosal/frontal projection neurons (CPN/FPN), with expression peaking early postnatally as axonal and dendritic targets are being reached and refined. CAV1 is localized to the soma and dendrites of CPN/FPN, a unique population of neurons that shares information both between hemispheres and with premotor cortex, suggesting function during postmitotic development and refinement of these neurons, rather than in their specification. Consistent with this, we find that Cav1 function is not necessary for the early specification of CPN/FPN, or for projecting to their dual axonal targets. CPN subtype-specific expression of Cav1 identifies and characterizes a first molecular component that distinguishes this functionally unique projection neuron population, a population that expands in primates, and is prototypical of additional dual and higher-order projection neuron subtypes.
\end{abstract}

Key words: axonal projections; connectivity; corpus callosum; neocortex; neuronal subtypes

\section{Significance Statement}

Callosal projections neurons (CPN) are a diverse set of neocortical interhemispheric excitatory projection neurons that integrate multiple distinct brain regions. While retrograde studies have identified CPN subpopulations that project to multiple targets, molecular identifiers are lacking for these subpopulations. Here, we identify Caveolin 1 (Cav1) as an identifier of CPN with dual callosal and ipsilateral frontal projections (CPN/FPN). CAV1 is expressed by over $80 \%$ of these CPN/FPN, with expression peaking early postnatally. CAV1 localizes to the soma and dendrites of CPN/FPN, suggesting function during postmitotic development and refinement of these neurons, rather than in their early specification. Identification of this molecular identifier of CPN/FPN will enable future functional investigations of this unique neuronal population. 


\section{Introduction}

The neocortex is composed of many distinct subtypes of neurons that developmentally form precise subtypespecific connectivity and circuitry to enable cortex to perform its many complex functions of sensory processing, associative integration, cognition, and motor output. Callosal projection neurons (CPN) are the broad population of commissural neurons that connect the cerebral hemispheres via the corpus callosum (CC). CPN are excitatory pyramidal projection neurons whose cell bodies reside in neocortical Layers II/III ( $~ 80 \%$ in mouse), V ( 20\%), and a few \% in VI (Ivy and Killackey, 1981; Silver et al., 1982; Catapano et al., 2001; Fame et al., 2011; Greig et al., 2013; MacDonald et al., 2013) and play multiple roles in complex associative and integrative cognition. CPN are a diverse set of subpopulations, distinguished by characteristics including cell body location, birthdate, electrophysiological and neurochemical properties, dendritic tree distribution, axonal target(s), and molecular expression (Aboitiz and Montiel, 2003; Mitchell and Macklis, 2005; Benavides-Piccione et al., 2006; Molyneaux et al., 2009; Fame et al., 2011; Otsuka and Kawaguchi, 2011; Fame et al., 2016a). While these properties describe and categorize CPN, they also determine the function(s) of diverse CPN subtypes.

Molecular controls that both define and regulate development of these distinct CPN subtypes are just beginning to be elucidated. A combinatorially-expressed set of genes that both define CPN as a broad population and distinguish novel subpopulations of CPN during development has been identified (Molyneaux et al., 2009), and a few molecular controls have been investigated functionally. For example, SATB2 regulates CPN identity throughout the neocortex; in the absence of its function, CPN project axons subcortically rather than across the $\mathrm{CC}$, and

Received July 5, 2017; accepted December 19, 2017; First published January 8, 2018.

The authors declare no competing financial interests.

Author contributions: J.L.M., R.M.F., and J.D.M. designed research; J.L.M., R.M.F., and E.M.G.-B. performed research; J.L.M. and R.M.F. analyzed data; J.L.M., R.M.F., and J.D.M. wrote the paper.

This work was supported by grants from the National Institutes of Health (R37 NS41590, with additional infrastructure support by NS45523, NS49553, and NS075672), the Jane and Lee Seidman Fund, the Emily and Robert Pearlstein Fund, and the United Sydney Association (to J.D.M); and by the National Science Foundation Graduate Research Fellowship Program fellowship and the National Institutes of Health Predoctoral NRSA Fellowship F31 NS073163 (to R.M.F)

$\S$ J.L.M. and R.M.F. contributed equally to this work.

J. L. MacDonald's present address: Department of Biology, Syracuse University, Syracuse, NY 13244.

Acknowledgements: We thank members of the Macklis lab for thoughtful discussions and input, in particular G. Cederquist for sharing expertise regarding CPN/BPN; and L. Pasquina, R. Richardson, C. Greppi, T. Keefe, and P. Davis for superb technical assistance.

*Correspondence should be addressed to either of the following: Jessica L. MacDonald at the above address, E-mail: jemacdon@syr.edu; Jeffrey D. Macklis at the above address, E-mail: jeffrey_macklis@harvard.edu.

DOI:http://dx.doi.org/10.1523/ENEURO.0234-17.2017

Copyright (C) 2018 MacDonald et al.

This is an open-access article distributed under the terms of the Creative Commons Attribution 4.0 International license, which permits unrestricted use, distribution and reproduction in any medium provided that the original work is properly attributed. they take on some molecular characteristics of corticofugal projection neurons (Alcamo et al., 2008; Britanova et al., 2008). Other molecular controls regulate specific aspects of CPN development, and/or distinct subpopulations. Cux1 and Cux2 regulate dendritic complexity and synapse formation of Layer II/III CPN (Cubelos et al., 2010), and Cux1 regulates activity-dependent interhemispheric connectivity of CPN (Rodríguez-Tornos et al., 2016). CITED2 regulates generation of Layer II/III CPN throughout the neocortex, as well as areal identity and neuronal connectivity specifically of somatosensory CPN (Fame et al., 2016b). CTIP1, on the other hand, regulates specification of deep layer CPN (Woodworth et al., 2016).

Caveolin 1 (Cav1) was identified in Molyneaux, et al. (2009) as a CPN subpopulation-restricted gene during neocortical development, with a peak of expression at postnatal day 3 (P3). Cav1 encodes a membrane-bound scaffolding protein necessary for a range of cellular processes, including functions related to the unique lipid raft structures it forms, caveolae. Cav1 is highly expressed broadly in developing blood vessels and endothelial cells, and is required for their proper development (Razani et al., 2001; Schubert et al., 2002), and for blood-brain barrier permeability (Zhao et al., 2014). While caveolae are not thought to exist in neurons (Head and Insel, 2007), Cav1 knock-out mice exhibit neurologic abnormalities including limb clasping, abnormal spinning, muscle weakness, reduced activity, and gait abnormalities (Trushina et al., 2006).

As a lipid raft scaffolding molecule, CAV1 interacts with multiple binding partners, some of which are particularly compelling as components of neuronal function. CAV1 binds directly to the calmodulin-dependent scaffolding protein striatin (Gaillard et al., 2001), which acts as a signaling platform in dendritic spine signal transduction (Benoist et al., 2006), and SNAP25, which complexes to CAV1 presynaptically on synaptic potentiation (Braun and Madison, 2000). CAV1 plays roles in neurotrophin response, and has the ability to interact with synaptosome complexes (Bilderback et al., 1997, 1999; Head and Insel, 2007). CAV1 is required for estrogen receptor $\alpha(\mathrm{ER} \alpha)$ activation of the metabotrophic glutamate receptor, mGluR $1 \alpha$, in hippocampal neurons, potentially acting in long-term depression (Takayasu et al., 2010). CAV1 provides a scaffold for both the $\mathrm{ER} \alpha$ voltage-dependent anion receptor and one of its interactors, the IGF-1 receptor (Maggi et al., 2002; Marin et al., 2009), a known positive regulatory pathway for corticospinal projection neuron axonal outgrowth (Ozdinler and Macklis, 2006).

Cav1 has additionally been implicated in neuronal differentiation from progenitors (Li et al., 2011), synaptic ribbons in photoreceptors (Kachi et al., 2001), and other neurotransmitter receptor functions including muscarinic cholinergic receptors and NMDA receptor NR2B (Lai et al., 2004). Further, CAV1 interacts with Rho-family GTPase RAC1, and this interaction has been directly implicated in neurite outgrowth (Kang et al., 2006). These neuronal-specific processes might account for some of the neurologic deficits in Cav1 loss-of-function mice de- 
scribed above, and additionally motivate this study of Cav1 in CPN.

Here, we further identify that Cav1 is highly expressed during axonal and dendritic development in a laminarlyand regionally-restricted subset of dual projecting CPN that extend both homotopic axonal connections to mirror image locations in the contralateral hemisphere, and rostral connections to ipsilateral frontal areas, sending information from sensory or motor functional areas to higher hierarchical cortical areas (here, these dual-projecting neurons are referred to as $\mathrm{CPN} /$ frontal projection neurons (FPN; Mitchell and Macklis, 2005). The majority of these CPN/FPN are located in neocortical Layer Va in both the primary somatosensory area (S1) and in a large expansion in caudo-lateral secondary somatosensory neocortex (S2; Mitchell and Macklis, 2005). While CPN/FPN have been identified anatomically, no molecular controls over this population's unique connectivity or function have been identified, limiting understanding of the development and function of these specialized dual-projecting neurons. Our investigations of Cav1 expression and function reported here identify and characterize a first molecular component that distinguishes and might control aspects of this functionally unique projection neuron population.

\section{Materials and Methods}

\section{Mouse lines}

All animal procedures were performed in accordance with the Harvard University animal care committee's regulations. Cav1-null mice on a congenic C57/BI6 background (B6.Cg-Cav1tm1M/s/J) were obtained from The Jackson Laboratory, strain number 007083 (RRID:IMSR_JAX:007083). The original targeted null mutation was generated by Michael Lisanti at The Albert Einstein College of Medicine. A 2.2-kb region of the gene including exons 1 and 2 and a portion of the promoter region was replaced with a neomycin resistance cassette via homologous recombination (Razani et al., 2001).

BTBR acallosal mice on a congenic background (BTBR $\left.T^{+} t f / J\right)$ were obtained from The Jackson Laboratory, strain number 002282 (RRID:IMSR_JAX:002282; Wahlsten et al., 2003). LP/J mice have been shown to be an appropriate callosal control population for BTBR mice. $\mathrm{LP} / \mathrm{J}$ mice (LP/J) were obtained from The Jackson Laboratory, strain number 000676 (RRID:IMSR_JAX:000676).

C57/BI6 wild-type (WT) mice were obtained from The Jackson Laboratory (RRID:IMSR_JAX:000664), and were used to breed with Cav1-null mice, and for birthdating and electroporation experiments. FEZF2 mutants were generated by Hirata et al. (2004; GenBank accession number: AB042399).

\section{Immunocytochemistry}

Immunocytochemistry was performed as follows. Briefly, brains were fixed by transcardial perfusion with PBS, followed by $4 \%$ paraformaldehyde, and postfixed overnight at $4^{\circ} \mathrm{C}$ in $4 \%$ paraformaldehyde. Brains were sectioned at $50 \mu \mathrm{m}$ on a vibrating microtome (Leica). Sections were blocked in $0.3 \%$ BSA (Sigma), $8 \%$ goat or donkey serum, and $0.3 \%$ Triton $\mathrm{X}-100$ (Sigma) for $1 \mathrm{~h}$ at room temperature (RT), before incubation in primary antibody. Secondary antibodies were selected from the Alexa Fluor series.

Antigen retrieval methods were required to expose antigens for some of the primary antibodies, including CAV1. Sections were incubated in $0.1 \mathrm{M}$ citric acid ( $\mathrm{pH}$ 6.0) for 10 $\min$ at $95-98^{\circ} \mathrm{C}$, and sections were rinsed in PBS before blocking. For thymidine analogues (IdU, CldU), $\mathrm{HCl}$ antigen retrieval was required. Tissue was rinsed quickly in $\mathrm{ddH}_{2} \mathrm{O}$ and incubated in $2 \mathrm{~N} \mathrm{HCl}$ for $2 \mathrm{~h}$ at $\mathrm{RT}$, and sections were rinsed in PBS before blocking.

Primary antibodies and dilutions were used as follows: rabbit anti-CAV1, 1:500 (Cell Signaling \#3238; RRID: AB_2072166); goat anti-LMO4, 1:200 (Santa Cruz Biotechnology SC- 11122; RRID:AB_648429); rat anti-CTIP2 1:500 (Abcam ab18465; RRID:AB_2064130), mouse antiBrdU, 1:500 (Becton Dickinson \#347580; clone B44; RRID:AB_10015219; detects IdU); rat anti-BrdU, 1:500 (Accurate \#OBT- 0030; clone BU1/75; RRID:AB_2313756; detects CldU); rabbit anti-GFP, 1:500 (Invitrogen; RRID: AB_221569); mouse anti-SATB2, 1:500 (Abcam ab51502; RRID:AB_882455); goat anti-BHLHB5, 1:200 (Santa Cruz Biotechnology SC-6045; RRID:AB_2065343); and rabbit anti-5-HT, 1:1000 (Immunostar 20080; RRID:AB_572263).

\section{In situ hybridization}

Nonradioactive colorimetric in situ hybridization was performed using probes labeled with digoxigenin (dig)UTP generated by reverse transcription PCR. The probe sequence for Cav1 was previously published (Molyneaux et al., 2009). Postnatal tissue was fixed overnight in $4 \%$ paraformaldehyde at $4^{\circ} \mathrm{C}$. Fixed tissue was sectioned on a VT1000S vibrating microtome (Leica Microsystems) to a thickness of $50 \mu \mathrm{m}$. Embryonic tissue was flash frozen in 2-methyl butane, embedded in TBS, and cryosectioned on a CM3050S cryostat (Leica Microsystems) to a thickness of $14 \mu \mathrm{m}$. Sense probes were used as negative controls in all experiments. Sections were mounted on Superfrost plus slides (Fisher Scientific) and postfixed in 4\% PFA in PBS for $10 \mathrm{~min}$, rinsed in PBS for $3 \mathrm{~min}$, permeabilized in $0.3 \%$ Triton $\mathrm{X}-100$ (Sigma) followed by RIPA cell lysis buffer (150 mM sodium chloride, 1\% Triton $\mathrm{X}-100,1 \%$ deoxicholic acid sodium salt, $0.1 \%$ sodium dodesil sulfate, $50 \mathrm{mM}$ Tris- $\mathrm{HCl}, \mathrm{pH} 7.5$, and 2 mM EDTA), refixed in 4\% PFA, acetylated for $15 \mathrm{~min}$ in $0.1 \mathrm{M}$ triethanolamine $/ 0.4 \% \mathrm{HCl} / 0.25 \%$ acetic anhydride (Sigma), and then preybridizied in $65^{\circ} \mathrm{C}$ hybridization buffer $[50 \%$ formamide, $5 \times$ SSC, $5 \times$ Denhardts ( $1 \mu \mathrm{g} / \mathrm{ml}$ Ficoll 400, 1 $\mu \mathrm{g} / \mathrm{ml}$ polyvinylpyrrolidone, $1 \mu \mathrm{g} / \mathrm{ml}$ BSA), $500 \mu \mathrm{g} / \mathrm{ml}$ sheared salmon sperm DNA, and $250 \mu \mathrm{g} / \mathrm{ml}$ yeast RNA]. Slides were incubated overnight $(14-20 \mathrm{~h})$ at $65^{\circ} \mathrm{C}$ in 2 $\mu \mathrm{g} / 17 \mathrm{ml}$ dig-labeled probe in hybridization buffer in a plastic mailer. Slides were then subjected to stringency washes in $2 \times$ SSC/50\% formamide/0.1\% Tween 20 at $65^{\circ} \mathrm{C}$ for $2 \mathrm{~h}$. Sections were then rinsed in MABT $[0.9 \mathrm{M}$ maleic acid (Sigma), 0.1 M NaCl (Sigma), 0.0005\% Tween 20 (Sigma), and $0.175 \mathrm{M} \mathrm{NaOH}$ (Sigma)] at RT, blocked in $10 \%$ goat serum in MABT, and incubated overnight in goat alkaline phosphatase-conjugated anti-dig (1:1000; Roche) primary antibody in block. The following day, the 
slides were rinsed with MABT, followed by a 30-min wash in alkaline phosphatase reaction buffer $(100 \mathrm{mM}$ Tris, $\mathrm{pH}$ 9.5, $50 \mathrm{mM} \mathrm{MgCl}_{2}, 100 \mathrm{mM} \mathrm{NaCl}$, and 0.1\% Tween 20). The alkaline phosphatase reaction was developed with $0.25 \mathrm{mg} / \mathrm{ml}$ nitro-blue tetrazolium (NBT)/125 $\mu \mathrm{g} / \mathrm{ml}$ 5-bromo-4-chloro-3'-indolyphosphate (BCIP) in phosphatase reaction buffer, changing to fresh solution every 1-4 $\mathrm{h}$ at RT or every 6-9 $\mathrm{h}$ at $4^{\circ} \mathrm{C}$. When the reaction was complete, tissue was rinsed in $0.1 \%$ Tween 20 in PBS, postfixed in 4\% PFA for $30 \mathrm{~min}$.

\section{Retrograde labeling of cortical projection neurons}

Perinatal retrograde labeling of CPN, corticospinal motor neuron (CSMN), Corticostriatal projection neurons (CStrPN), and Anterior commissure projecting neurons $(A C N)$

Perinatal retrograde labeling of $\mathrm{CPN}$, and CSMN was performed using a Vevo 770 ultrasound backscatter microscopy system (VisualSonics). Briefly, P1 pups of either sex were anesthetized by hypothermia, and CC, or pons, respectively, were injected under ultrasound guidance using a pulled glass micropipette (tip diameter, 80-100 $\mu \mathrm{m})$, and cell bodies were labeled with the $\beta$-subunit of cholera toxin (CTB) labeled with Alexa Fluor dye $(2 \mathrm{mg} / \mathrm{ml}$, Invitrogen). For CSMN, six 23-nl injections of cholera toxin subunit B $(2 \mu \mathrm{g} / \mu \mathrm{l})$ were deposited bilaterally into the pons. The brains were harvested $2 \mathrm{~d}$ after injection (P3).

Because CStrPN reach the striatum later than P1, pups were anesthetized with hypothermia and injected sterotaxically at P3. The striatal injection point is very close to the anterior commissure in the developing brain, so both CStrPN and ACN were labeled simultaneously. The injections were made at an angle of $32.5^{\circ}$ from horizontal, 3 $\mathrm{mm}$ posterior to bregma, and $1.8 \mathrm{~mm}$ lateral (left). The CTB labeled with Alexa Fluor dye (2 $\mathrm{mg} / \mathrm{ml}$, Invitrogen) was injected at a depth of $4.2 \mathrm{~mm}$, and $4.6 \mathrm{nl}$ of dye was delivered three times (total of $13.8 \mathrm{nl}$ ) into three injection sites at depths, 4.2, 4.1, and $4.0 \mathrm{~mm}$. The needle was removed after 5 min to allow diffusion and avoid retracting the dye with the needle. The brains were harvested $2 \mathrm{~d}$ after injection (P5).

\section{Postnatal dual CPN/FPN and CPN/BPN retrograde labeling}

P6 pups were anesthetized with hypothermia. P21 mice were deeply anesthetized with Avertin $(0.02 \mathrm{ml} / \mathrm{g}$ body weight, i.p.). Tracers were injected transcranially with sharp pulled glass micropipettes (tip diameter 80-100 $\mu \mathrm{m}$ ) in presumptive premotor and sensory-motor areas, as described below. Double fluorescent tracer injections were performed to label simultaneously: (1) CPN in sensory-motor cortex, and (2) FPN with long-distance ipsilateral projections to the premotor cortex. CPN with projections to the contralateral neocortex were labeled with Alexa Fluor 647-conjugated cholera toxin subunit- $\beta$ ( $2 \mathrm{mg} / \mathrm{ml}$, Invitrogen) with 25 injection sites, $46 \mathrm{nl}$ (10 injections of $4.6 \mathrm{nl}$ ) each site at a depth of $250 \mu \mathrm{m}$ at P6 and $450 \mu \mathrm{m}$ at P21. The most caudal injection site was 1 $\mathrm{mm}$ caudal to bregma, and the most rostral injection site was $\sim 1 \mathrm{~mm}$ caudal to the olfactory bulbs. All other injections were evenly spaced to complete the $5 \times 5$ grid.
Ipsilateral corticocortial projections to the premotor cortex were simultaneously retrogradely labeled with injections of Alexa Fluor 555-conjugated cholera toxin subunit B (2 mg/ml, Invitrogen) with seven injection sites, $46 \mathrm{nl}$ each site and a depth of $250 \mu \mathrm{m}$ at P6 and $450 \mu \mathrm{m}$ at P21. Brains were harvested $2 \mathrm{~d}$ after injection (P8).

Backward projecting neurons (BPNs) were retrogradely labeled via transcranial injection of cholera toxin subunit $B$ (2 $\mathrm{mg} / \mathrm{ml}$, Invitrogen) at P7 into the ipsilateral caudal cortex, covering the area of the presumptive somatosensory cortex. The most rostrolateral injection site was 1.5 $\mathrm{mm}$ rostral to lambda, and $2.5 \mathrm{~mm}$ lateral to the midline. All other injections were evenly spaced to complete the $3 \times 4$ grid. Each mouse received ten $4.6 \mathrm{nl}$ volume injections at 12 injection sites. For each injection site, five injections were made at $200 \mu \mathrm{m}$ depth from the dorsal surface of the brain, two injections at $150 \mu \mathrm{m}$ depth, 1 injection at $100 \mu \mathrm{m}$ depth, and two injections at $50 \mu \mathrm{m}$ depth. Brains were harvested $2 \mathrm{~d}$ after injection (P9).

Small punctures were made in the skull at the location of each injection point with either a pulled glass pipette (P6) or a fine suture needle (P21) before lowering the injection needle to the proper depth. This avoided the need for large craniotomies, thus minimizing insult and enhancing recovery time, while allowing for exact depth measurements to be made accurately. For all retrograde labeling experiments, our approaches minimized surgical time and insult; thus, morbidity was very low, and the survival rate was near $100 \%$.

\section{Birthdating}

For IdU and CldU birthdating, equimolar delivery of IdU (57.5 mg/kg) or CldU (42.5 mg/kg) was performed by intraperitoneal injections at 12-h intervals from embryonic day (E) E11 to E15.5 (Vega and Peterson, 2005), calculating embryonic age with E0.5 as the morning of observed vaginal plug. Mice of either sex were perfused at P6, and brains prepared for immunocytochemistry.

\section{Gain-of-function constructs}

For control gain-of-function experiments, a vector containing a constitutively active CMV enhancer/ $\beta$ actin promoter driving GFP downstream of an internal ribosomal entry site (IRES) was used (GFP ${ }^{\text {control }}$, generous gift of $\mathrm{C}$. Lois, MIT (Molyneaux et al., 2005). For the Cav1 overexpression construct, called Cav1 ${ }^{\text {GFP }}$, full-length Cav1 cDNA was cloned into the same vector backbone using a Sal1/Not1 digest (New England Biolabs, Ipswich, MA) of the Cav1 cDNA from a pSport1 vector purchased from Open Biosystems (clone ID 30062454). A sequenced clone with perfect alignment to the NCBI reference sequence NM_007616 in both the sense and antisense orientations was selected for experiments.

\section{In utero electroporation}

In utero electroporations were performed essentially as described previously (Saito and Nakatsuji, 2001; Molyneaux et al., 2005; Saito, 2006). Timed pregnant mice were deeply anesthetized with isofluorane. Hair was removed from the abdomen, and the dam was secured supine on a heated surgical platform. Individual pups 
Table 1. Statistical Analyses Performed

\begin{tabular}{|c|c|c|c|c|c|c|}
\hline & Data structure & Type of test & $n$ (WT; KO) & $p$ value & $\begin{array}{l}\text { Observed } \\
\text { power }\end{array}$ & $95 \%$ confidence interval \\
\hline Fig. $6 \mathrm{G}, \mathrm{S} 2$ & Gaussian & Unpaired $t$ test & $(6 ; 6)$ & 0.2831 & 0.4278 & $-21.05-64.72$ \\
\hline Fig. $6 \mathrm{H}, \mathrm{S} 2$ & Gaussian & Unpaired $t$ test & $(6 ; 6)$ & 0.3004 & 0.4050 & $-18.72-54.72$ \\
\hline Fig. 6I, S1 & Gaussian & Unpaired $t$ test & $(6 ; 6)$ & 0.4529 & 0.4529 & $-0.3069-0.1476$ \\
\hline Fig. 6I, S2 & Gaussian & Unpaired $t$ test & $(6 ; 6)$ & 0.6214 & 0.6214 & $-0.1722-0.1081$ \\
\hline
\end{tabular}

were withdrawn from the abdominal cavity and moistened with sterile $37^{\circ} \mathrm{C} 1 \times$ PBS. Using a Vevo 770 ultrasound backscatter microscopy system (VisualSonics) to visualize the lateral ventricles, a beveled glass micropipette (50 $\mu \mathrm{m}$ width) was inserted into one lateral ventricle of each injected pup, and fifteen $69 \mathrm{nl}$ volume injections of prepared DNA mixture were delivered to the ventricle. Soon after retracting the glass micropipette, electric current was applied to the head of the embryo through two $1-\mathrm{cm}$ diameter platinum electrodes, orienting the current to drive the negatively charged DNA into the dorsal telencephalon. Five 25-V pulses of $50 \mathrm{~ms}$ duration at 1-s intervals were delivered using a CUY21EDIT square wave electroporator (Nepa Gene). Each injected embryo was gently returned to the abdominal cavity, and the next selected embryo was carefully withdrawn. No more than six embryos of either sex were injected per dam. The abdomen was sutured. Dams recovered on a warm heating pad, and once ambulatory were administered $250 \mu \mathrm{l}$ of buprenorphine $(0.015 \mathrm{mg} / \mathrm{ml}$ sterile PBS) before returning to their cages.

\section{Quantification of FPN/CPN}

For P8 quantification of CAV1-expressing CPN/FPN, anatomically matched sections were selected ( $n=4 \mathrm{WT})$, and CAV1 immunocytochemistry was performed. Digital boxes of fixed width indicated each of the four cortical regions, and the number of CPN/FPN and CAV1 ${ }^{+} \mathrm{CPN} /$ FPN were counted. Percentages of FPN/CPN that express CAV1 in each region were calculated from total numbers. Error bars or \pm indicate the SEM. Individuated neuronal somata were counted for each assignment; it was not possible to count all CPN or CAV1-expressing neurons in some densely packed microdomains due to high neuronal density.

For P8 quantification of CPN/FPN in Cav1-null mice, anatomically matched sections were selected $(n=6 \mathrm{WT}$, $n=6 \mathrm{Cav}^{-1-}$ ). Digital boxes of fixed width indicated the S1 or S2 cortical regions, and the number of CPN/FPN, and FPN were counted in S1 and S2. The percentage of FPN with concurrent callosal projections was also calculated. No significant differences were detected between WT and $\mathrm{Cav1}^{-1-}$. Error bars or \pm indicate the SEM. Data were analyzed by unpaired Student's $t$ test. Statistical analyses were performed in Prism (GraphPad Software, Inc.). A two-tailed post hoc observed power was calculated from Cohen's $d$, the $p$ value, and $n$ (Table 1).

\section{Microscopy and image analysis}

Whole mount images were acquired using an SMZ1000 fluorescence dissecting microscope (Nikon) with a SPOT CCD digital camera (Diagnostic Instruments) and SPOT acquisition software.

Tissue sections were imaged on a Nikon E1000 microscope (Nikon Instruments) equipped with an XCite 120 illuminator (EXFO) and Q-imaging Retixa EX cooled CCD camera (Q-imaging Corp), or a Nikon 90i microscope using a 1.5-megapixel cooled CCD digital camera (Andor Technology), a five-megapixel color CCD digital camera (Nikon Instruments). Images were collected and analyzed with Volocity image analysis software (version 4.0.1; Improvision Inc.) or Elements acquisition software (Nikon Instruments).

Laser confocal analysis was performed using a Bio-Rad Radiance 2100 confocal microscope with LaserSharp2000 imaging software (Bio-Rad Laboratories). Images were processed using a combination of functions provided by ImageJ (Rasband, W.S., ImageJ; http://imagej.nih.gov/ij/, 1997-2011.) and Adobe Photoshop/Illustrator software packages (Adobe).

\section{Results}

\section{CAV1 is expressed by a restricted population of CPN, and is excluded from CSMN}

Cav1 is highly expressed by CPN relative to CSMN in the developing neocortex, with a peak of expression between P3 and P6 (Molyneaux et al., 2009), during the critical time when CPN are making axonal and dendritic connections. Cav1 is not detected in CPN by P14. We more thoroughly investigated CAV1 expression by immunocytochemistry, and similarly identified that CAV1 is indeed expressed by CPN in cortical Layer $\mathrm{Va}$, and is excluded from subcerebral projection neurons (SCPN; of which CSMN are a subpopulation) by combining CAV1 immunocytochemistry and dual retrograde labeling of CPN (from the contralateral cortex) and SCPN (from the pons; Fig. $1 A-C)$. The CAV1-expressing population of CPN is clearly superficial to the SCPN (Fig. 1C), and CAV1 is coexpressed with SATB2 (Fig. 1D), which is expressed by CPN and excluded from SCPN. CAV1 expression is unchanged in Fezf2 loss-of-function neocortex, in which no subcerebral neurons are specified (Molyneaux et al., 2005), confirming that CAV1 is excluded from CSMN (Fig. $1 E, F)$. The highly restricted expression pattern suggests that Cav1 functions in a very specific subpopulation of $\mathrm{CPN}$, rather than playing a broad role in CPN development (Figs. 1, 2). 
A
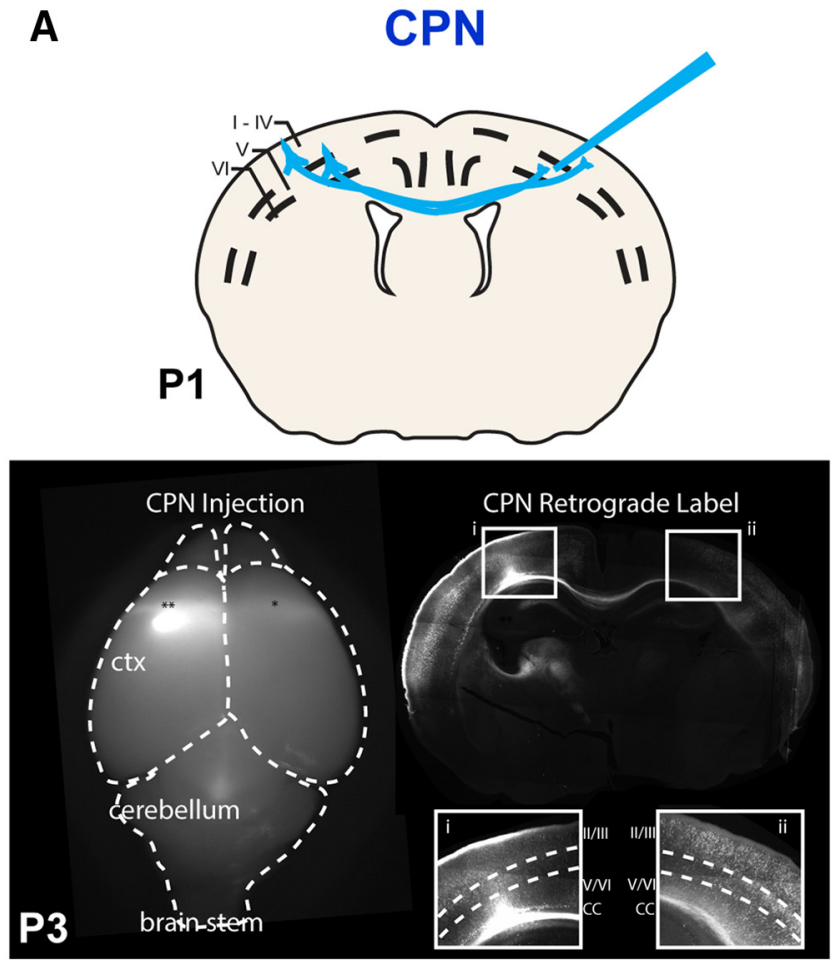

B
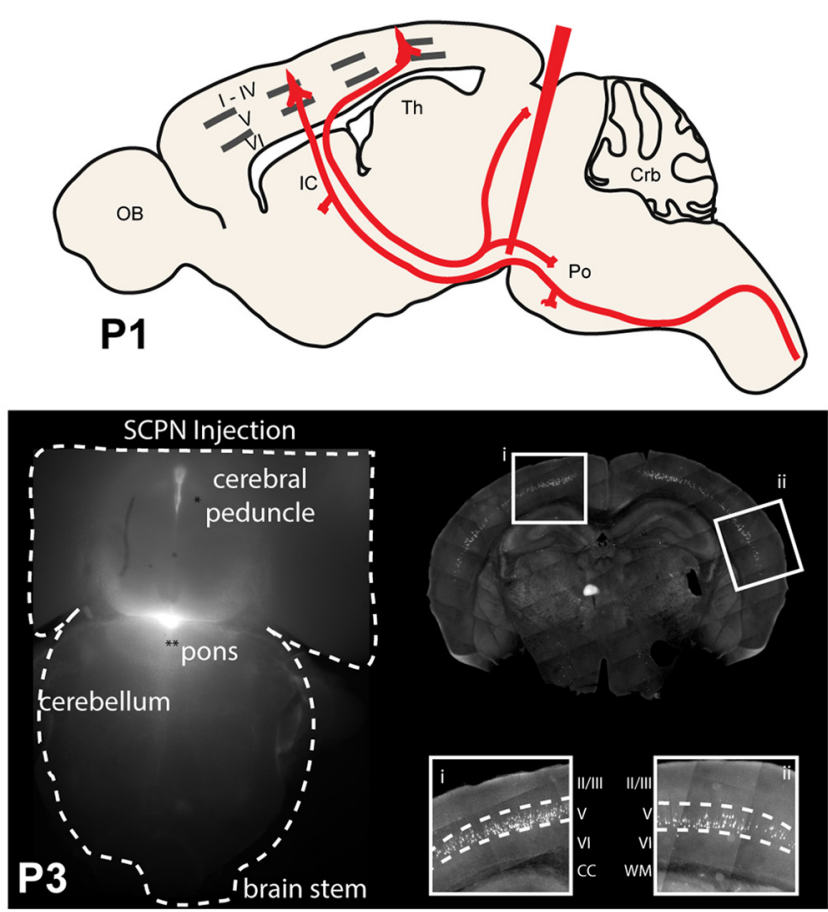

P3
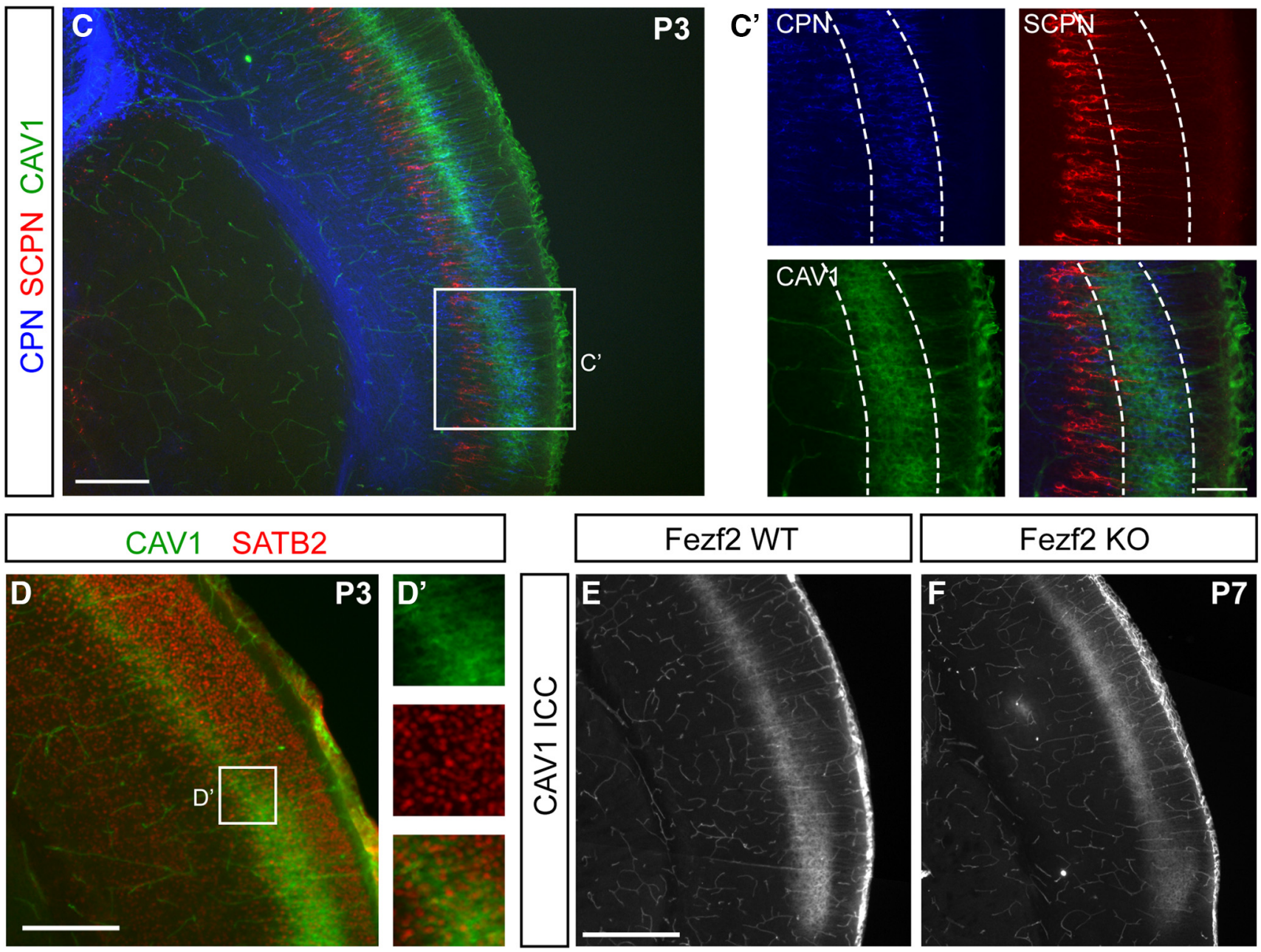

Figure 1. CAV1 is expressed by CPN and excluded from SCPN at P3. $\boldsymbol{A}, \boldsymbol{B}$, Retrograde labeling was performed at P1 by injecting 


\section{continued}

$\mathrm{CTB}_{647}$ into the contralateral hemisphere to label CPN $(\boldsymbol{A})$ and $\mathrm{CTB}_{555}$ into the pons to label SCPN (B). Example images of retrogradely-labeled brains are shown at P3, including wholemount images of the injection sites (dorsal view for CPN, ventral view for SCPN) and coronal sections showing the laminar distribution of the labeled neurons. C, C', CAV1 (green) immunocytochemistry at P3 reveals that CAV1 is expressed in Layer V, with a caudo-lateral distribution similar to SCPN (red). However, CAV1 (green) colocalizes with retrogradely labeled CPN (blue) in Layer Va, and it is excluded from SCPN (red) in Layer Vb. The box in $\boldsymbol{C}$ indicates the region of higher magnification images in $\boldsymbol{C}^{\prime}$. $\boldsymbol{D}$, CAV1 expression (green) overlaps with the CPN developmental control SATB2 (red), reinforcing that CAV1 is expressed by CPN. $\boldsymbol{E}, \boldsymbol{F}$, CAV1 expression is not altered in Fezf2-null cortex $(\boldsymbol{F})$, which is developmentally devoid of SCPN, reinforcing that CAV1 is not expressed by SCPN. Scale bars: $250 \mu \mathrm{m}(\boldsymbol{C}), 100 \mu \mathrm{m}\left(\boldsymbol{C}^{\prime}\right), 250 \mu \mathrm{m}(\boldsymbol{D})$, and $500 \mu \mathrm{m}(\boldsymbol{E}$, F); IC, internal capsule; Th, thalamus; OB, olfactory bulb; Po, pons; Crb, cerebellum; roman numerals indicate cortical layer.

Developmentally, Cav1 mRNA is not detected in pallial progenitors or the cortical plate at $\mathrm{E} 13.5$, but it is detected in the caudo-lateral cortical plate by E15.5 (Fig. 2A). Both Cav1 mRNA and CAV1 protein are detected in cortical neurons at E18.5 (in addition to developing blood vessels), are highly expressed at P3 and P6, and are no longer detectable by P14 (Fig. 2B,C). Cav1-expressing neurons are distributed uniquely in cortical Layer Va, especially in caudo-lateral areas. This pattern is not a developmental gradient, and is maintained specifically at all developmental ages at which Cav1 is expressed (Fig. 2).

Interestingly, CAV1 expression is restricted at P8 to a subpopulation of CPN extending in Layer Va throughout primary somatosensory cortex (S1), and expanding in the caudo-lateral cortex (S2), and auditory cortex (A1) more caudally, but is mostly excluded from motor cortex (M1). This exclusion is clear by comparison between CAV1 immunocytochemistry and LMO4, which is highly expressed by CPN in motor cortex, but excluded from Layer II/III CPN in somatosensory cortex (Azim et al., 2009; Huang et al., 2009; Fig. 3A). This area-specific expression further supports subpopulation-specific function of CAV1 in CPN. Because of the strong expression of CAV1 at all developmental ages in Layer Va, particularly in caudolateral areas close to archicortex, where canonical cortical neuron subpopulations are not maintained, we investigated whether CAV1-expressing neurons exclude CTIP2, the canonical postmitotic SCPN control transcription factor highly expressed by specific SCPN Layer V populations (Arlotta et al., 2005; Chen et al., 2008). There is very little overlap between CAV1 and CTIP2 in S1 (Fig. 3B), although a small subset of CAV1-expressing neurons in far caudo-lateral S2 express CTIP2 (Fig. 3C). Based on size and morphology, these CAV1 ${ }^{+} / \mathrm{CTIP}^{+}{ }^{+}$neurons appear to be pyramidal projection neurons; however, they do not appear to project subcerebrally, as determined by the lack of overlap between CAV1 and retrogradelylabeled SCPN (Fig. 1). This quite unique population of non-SCPN, CTIP2 ${ }^{+}$neurons has not been extensively defined, but they might be a subpopulation of neurons with a transient developmental spinal projection that is later lost (Polleux et al., 2001; Arlotta et al., 2005).

To investigate more deeply what subpopulation(s) of CPN express CAV1, we examined expression of CAV1 in comparison to lamina-restricted molecular markers (Fig. $3 D$ ). CAV1 is coexpressed with Bhlhb5, which is expressed in Layers II-V, while CAV1 is expressed below the Layer IV barrel field, as indicated by 5-HT expression. Thus, CAV1 is expressed in Layer V. Further, to better delineate the population(s) and to enable optimal targeting of the population via in utero electroporation in future experiments, we performed birthdating analysis with thymidine analogs every $12 \mathrm{~h}$ throughout corticogenesis. These experiments reveal that CAV1-expressing neurons are born between E12.5 and E13.5, consistent with the dominant birthdate ranges for neocortical neurons residing in Layer $\mathrm{V}$ (Fig. 3E). CAV1-expressing neurons in caudo-lateral S2 cortex might be born a few hours earlier (peak at E12.5) than those of S1 Layer V (peak at E13.5).

\section{CAV1 is expressed by over $80 \%$ of dual-projecting FPN/CPN}

Development of CPN does not end when early progenitors are specified but, rather, includes acquisition of specific CPN subpopulation identities. Beyond the fact that CAV1 is highly expressed by CPN compared to CSMN overall, it is further quite specifically expressed in a very restricted pattern in neocortex. Because many uniquely projecting subpopulations of CPN reside in restricted cortical areas (in particular, within Layer V; Fame et al., 2011), and because the location of maximal CAV1 expression was reminiscent of the location of dual projecting neurons in mouse neocortex (Mitchell and Macklis, 2005), we investigated potential CAV1 expression by forward projecting neurons from somatosensory cortex to frontal areas $(\mathrm{FPN})$, backward projecting neurons (BPN), CPN with contralateral striatal projections $\left(\mathrm{CStrPN}_{\mathrm{i}}\right)$, and commissural neurons with anterior commissure projections (ACN; Fig. $4 A-D)$. The pattern of CAV1 expression closely resembles the restricted location of dual projecting FPN/ CPN (Mitchell and Macklis, 2005), and partially overlaps with the location of CStrPN $\mathrm{N}_{\mathrm{i}}$ and $\mathrm{ACN}$ in the most lateral regions. Expression is highest at the time of axon and dendrite extension, and formation and stabilization of neuronal connections (P3; Fig. 2). The rostral location of BPN does not overlap with the CAV1-expression domain, indicating that CAV1 is not expressed by all dual projecting CPN populations; CAV1 expression is quite specific. Although some CStrPN//ACN are located within the CAV1-expression domain laterally, the location of FPN/ CPN closely overlaps with the CAV1-expression domain, suggesting that CAV1 might be specifically important for CPN/FPN development, connectivity, and/or function (Fig. 4).

To confirm more deeply at the individual neuron level whether CAV1 is expressed by the dual projecting FPN/ CPN subpopulation, we retrogradely colabeled callosaland frontal-projecting neurons by stereotaxic injection of 

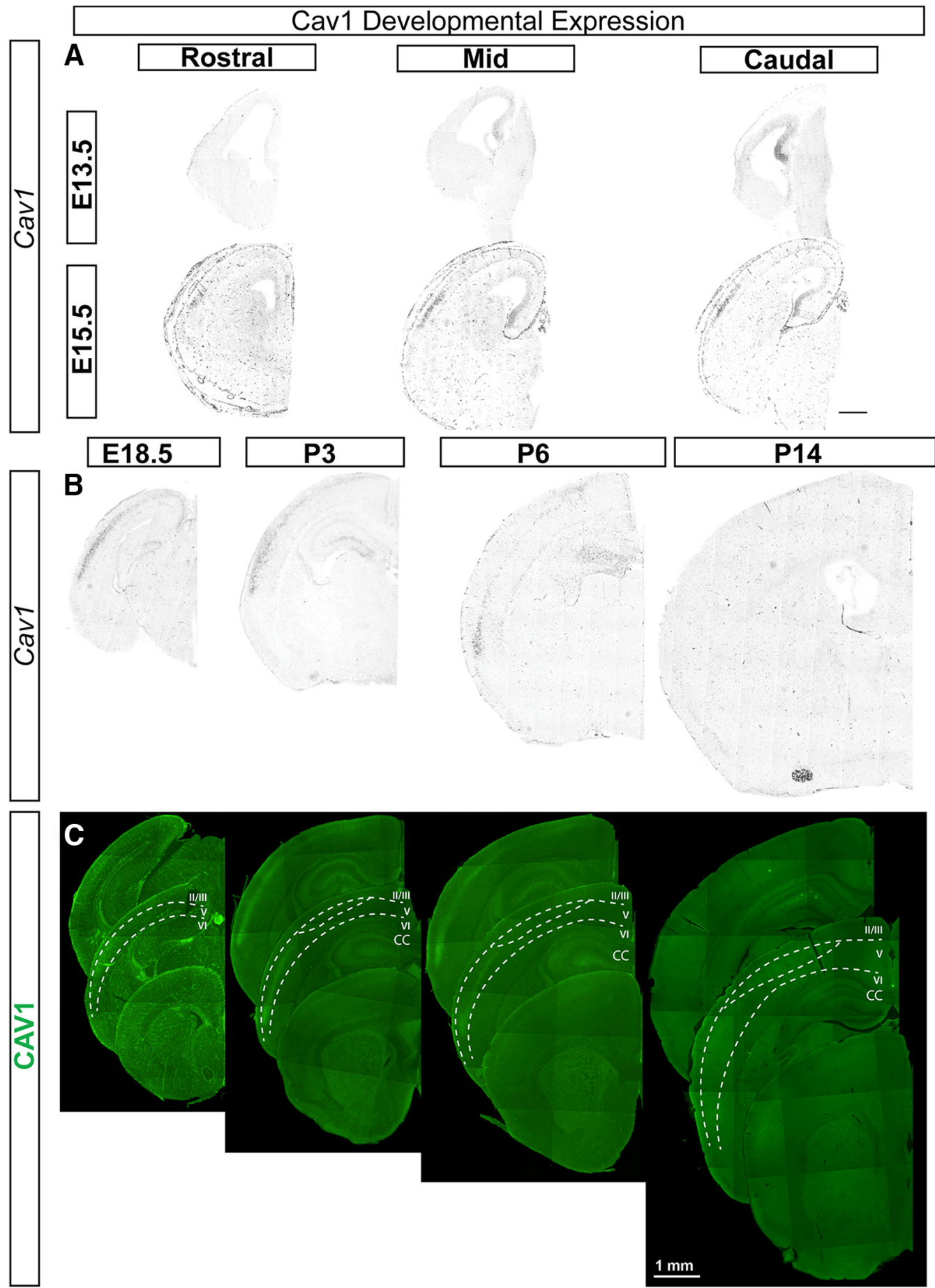

Figure 2. CAV1 is expressed in caudo-lateral cortex during mid-stage cortical development. $\boldsymbol{A}$, Cav1 mRNA is not detected in pallial progenitors or cortical plate at E13.5 but is detected in the caudal cortical hem. By E15.5, Cav1 is expressed in the caudo-lateral cortical plate. B, To determine whether Cav1 expression follows a developmental gradient, we examined expression at later embryonic stages through postnatal development. Cav1 mRNA is expressed by a restricted population of Layer Va cells (presumptive $\mathrm{CPN}$ ) in the caudo-lateral cortex from late embryonic stages (E18.5) through early postnatal development (P3, P6), with expression reduced in the cortex by $\mathrm{P} 14$. C, CAV1 protein is detected in a similar pattern to Cav1 mRNA throughout development. CAV1 is expressed by CPN within the same caudo-lateral Layer Va region throughout late embryonic and early postnatal development, suggesting that it is not following a developmental gradient. Scale bar: $1 \mathrm{~mm}$; E, embryonic day.

CTB conjugated to two different Alexa Fluor fluorophores into the contralateral somatosensory cortex and the ipsilateral premotor cortex, respectively (Fig. 4E,F). CAV1 overlaps with the entire domain of FPN, which also exist in other sensory modalities, including A1 (Mitchell and Macklis, 2005). We verified the proportion of CPN/FPN 


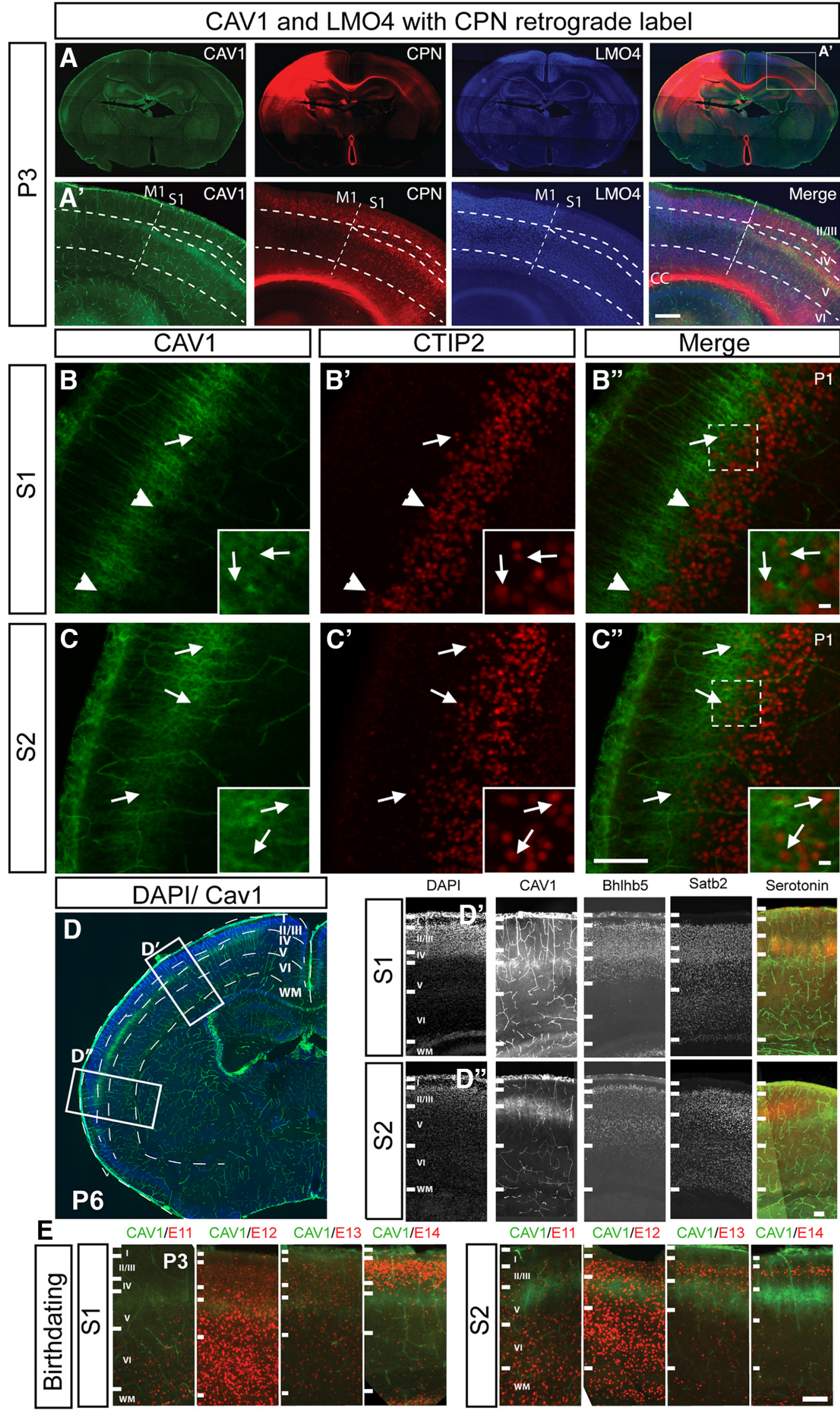

Figure 3. CAV1 is expressed by Layer Va CPN in an areally restricted fashion. $\boldsymbol{A}, \boldsymbol{A}^{\prime}$, Expression of CAV1 is areally restricted; CAV1 
continued

(green) is highly expressed by CPN (red; $\mathrm{CTB}_{555}$ retrograde label) throughout primary and secondary somatosensory cortex (S1 and $\mathrm{S} 2)$. CAV1 expression is not readily detected in CPN within motor cortex (M1), as delineated by Layer II/III expression of LMO4 (blue). $\boldsymbol{A}^{\prime}$, Inset from $\boldsymbol{A}$. Dashed line indicates M1-S1 boundary and cortical lamina. $\boldsymbol{B}$, In S1, CAV1 (green) is largely excluded from the CTIP2 (red)-expression domain (arrowheads) indicating SCPN, with only a small subpopulation of CTIP2+ve neurons extending into the CAV1-expression domain (arrow). C, In S2, the boundary between CAV1 (green) and CTIP2 (red) is not as clearly defined, with more CTIP2 + ve neurons interspersed with CAV1 (arrows). Regions of higher magnification insets are indicated in $\boldsymbol{B}$ " and $\mathbf{C}$ '. $\boldsymbol{D}$, At P6, CAV1 is expressed in Layer V, within the Satb2 and Bhlhb5-expressing domain, and below the serotonin-expressing barrel cortex in Layer IV. Regions of higher magnification insets are indicated in $\boldsymbol{D}$ "' and $\boldsymbol{D}$ ". $\boldsymbol{E}$, CAV1-expressing neurons are born between days E12.5 and E13.5 in both S1 and S2. deoxyuridine analogs (CldU or IdU) were injected at 12-h intervals throughout corticogenesis, and immunocytochemistry for BrdU (red) and CAV1 (green) was performed at P3, revealing that CAV1-expressing neocortical neurons, both in S1(somatosensory Layer V) and S2 (caudolateral expansion), are born between E12.3 and E13.5. Scale bars: $500 \mu \mathrm{m}\left(\boldsymbol{A}^{\prime}\right)$ and $100 \mu \mathrm{m}(\boldsymbol{B}-\boldsymbol{E})$.

that express CAV1 in S1 and S2, since they represent the major population of CPN/FPN. We found that over $80 \%$ of dual projecting CPN/FPN are CAV1 ${ }^{+}$, and only a small population of non-dual projecting cortical neurons expresses CAV1; CAV1 expression is thus highly restricted to and quite specific for this dual projecting population (Fig. 4F). Although the membranous location of CAV1 protein and the incomplete label generated by CTB injections preclude equivalent and reciprocal quantification of the percentage of $\mathrm{CAV} 1^{+}$cortical neurons that are dualprojecting, the domains map closely to the single neuron level.

\section{CAV1 is localized to CPN cell bodies and dendrites, and expression is not dependent on correct callosal connectivity}

CAV1 is a membrane-bound scaffolding protein, so its subcellular distribution might provide insight into its function(s) in specific neuronal subtypes. We investigated the subcellular localization of CAV1 in P3 CPN, and found it to be highly localized around the soma, extending throughout the apical dendrite and dendritic tuft (Fig. 5A). The same subcellular localization is observed at later stages of development (P7, data not shown). CAV1 is not highly detected in axons. This suggests potential roles for CAV1 in migration and/or dendrite function, although function at lower concentration in axons or growth cones is not excluded. Further, we generated a Cav1-IRES-GFP overexpression construct, and exogenously overexpressed Cav1 in Layer II/III CPN of somatosensory cortex via in utero electroporation at E15.5. Superficial layer CPN, which do not normally express Cav1, show a similar cellular distribution of CAV1 to that of endogenous neurons, with strong localization around CPN somata and in apical dendrites at P6 (Fig. 5B). This is in direct contrast to overexpressed GFP, which is evenly distributed throughout the neuronal soma, dendritic arbor, and axons, in which it is readily detectable (Fig. $5 C, B^{\prime \prime}$ ).

Since CAV1 is known to interact with striatins for correct signal transduction at synapses (Gaillard et al., 2001), and with multiple neurotransmitter receptors (Boulware et al., 2007; Takayasu et al., 2010), we considered that CAV1 expression might be regulated by neuronal activity. However, based on the early neonatal expression of CAV1, we hypothesized that final connectivity is not needed for CAV1 expression. To investigate whether CPN connectivity is required for postnatal CAV1 expression, we investigated whether CAV1 expression is altered in acallosal BTBR mice (Wahlsten et al., 2003). The BTBR mouse strain exhibits otherwise largely normal cortical development, but no axons extend across the CC. Although they perform quite well on physical coordination tasks, they display behavioral abnormalities. Additionally, these mice exhibit a reduced hippocampal commissure, accompanied by improper wiring reflected by tangles of axons known as probst bundles. These experiments reveal that CAV1 expression is independent of correct callosal connectivity, and CAV1 is expressed normally in P4 BTBR neocortex (Fig. 5D). Taken together, these results indicate that, although CAV1 had been previously shown to act at synapses (Gaillard et al., 2001), its expression by developing CPN is not dependent on correct connectivity.

\section{Cav1 function is not necessary for dual-projecting FPN/CPN to reach their axonal targets}

Because CAV1 is expressed by the overwhelming majority of dual-projecting FPN/CPN at P8, and most highly at P3, and although it not enriched in axons, we investigated whether Cav1 might be necessary for the correct maturation and/or maintenance of this specific subpopulation of CPN. However, because of its subcellular localization to the somato-dendritic compartments, we hypothesized that CAV1 would not be necessary for axonal guidance or targeting. We first investigated whether axons of FPN/CPN initially reach their targets correctly in the absence of Cav1 function, which would indicate that Cav1 is not necessary for axonal extension, pathfinding, or establishment of CPN connectivity. We retrogradely labeled FPN/CPN in both Cav1-null mice and their WT littermates at P6, as described previously, and examined them at P8 (Fig. 6). At this relatively early time (P8), when CPN exuberance is most pronounced, there is no difference in the overall number of FPN/CPN between Cav1null and WT mice (Fig. 6G), including within the secondary somatosensory cortical area (S2), where both CAV1 expression and the abundance of FPN/CPN change dramatically. Thus, as predicted by its subcellular localization, Cav1 function is not required for CPN/FPN to extend dual-projecting axons to specific targets. Since CAV1 is localized around neuronal cell bodies and dendritic trees, but not substantially in axons, it is not surprising that FPN/CPN reach their targets at P8, further supporting somato-dendritic-specific function for Cav1. 

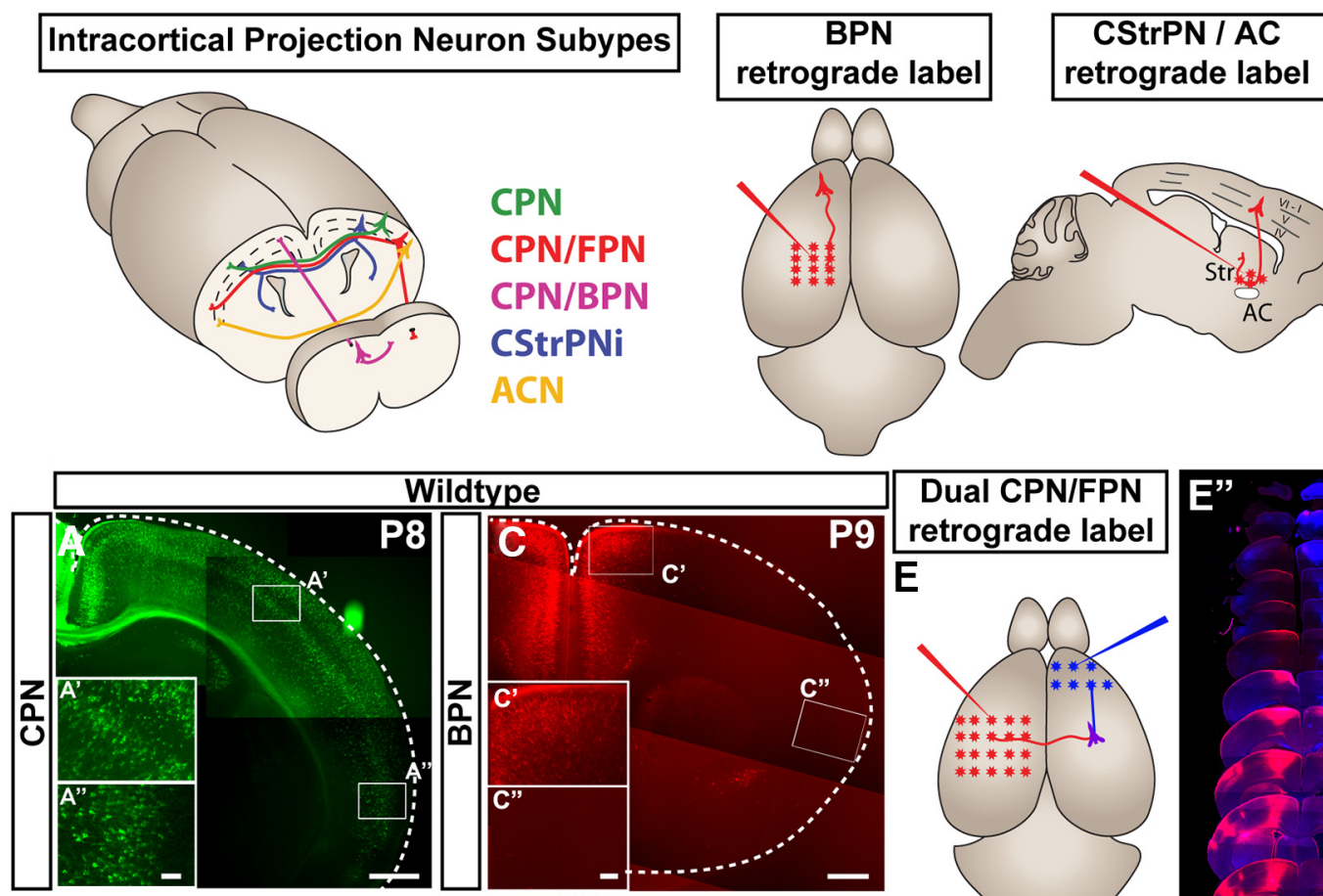

\section{Wildtype}
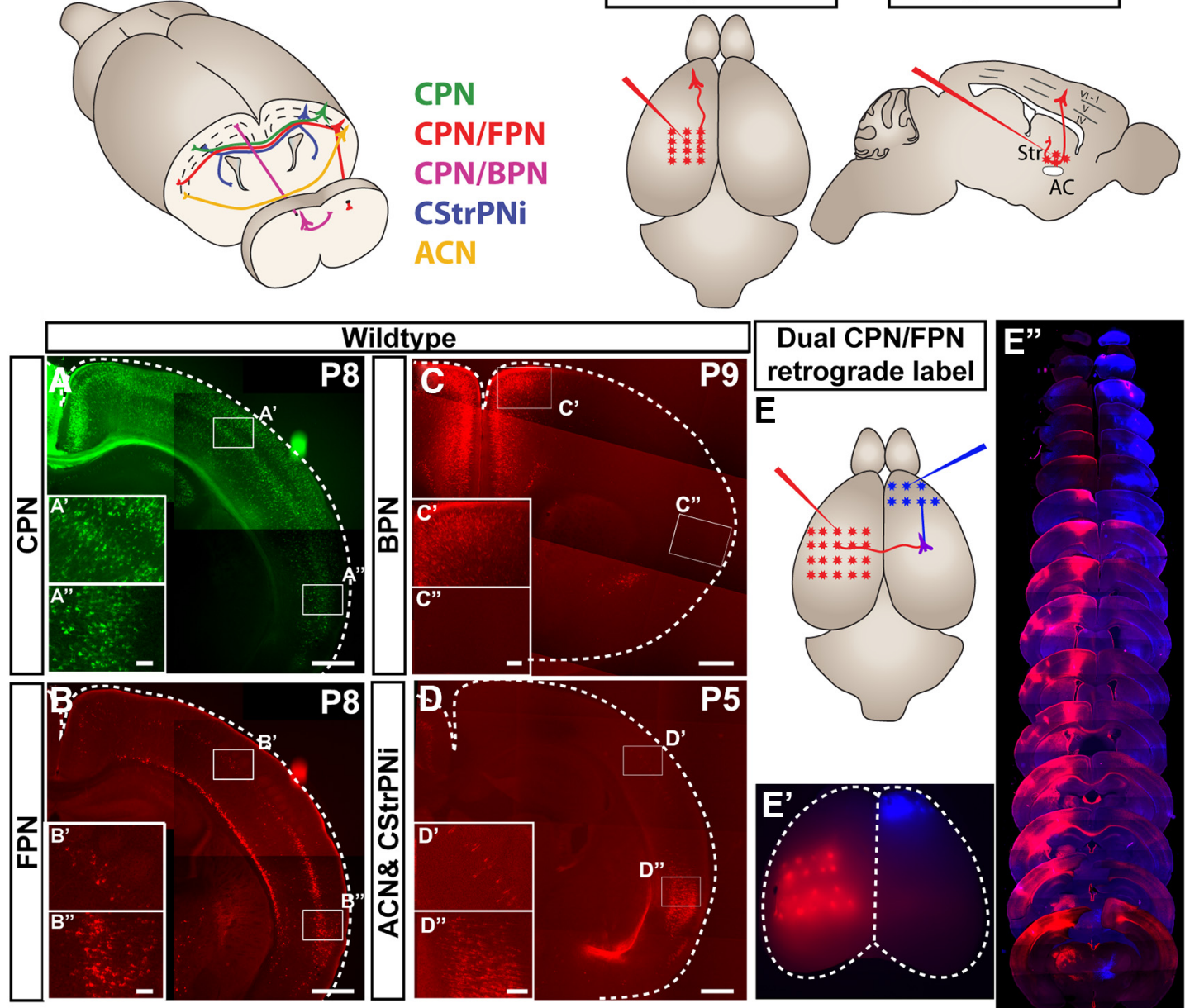

\section{Dual CPN/FPN retrograde label}

E

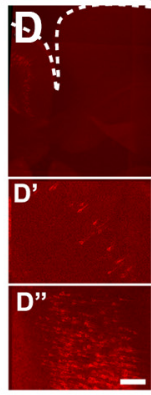

P5
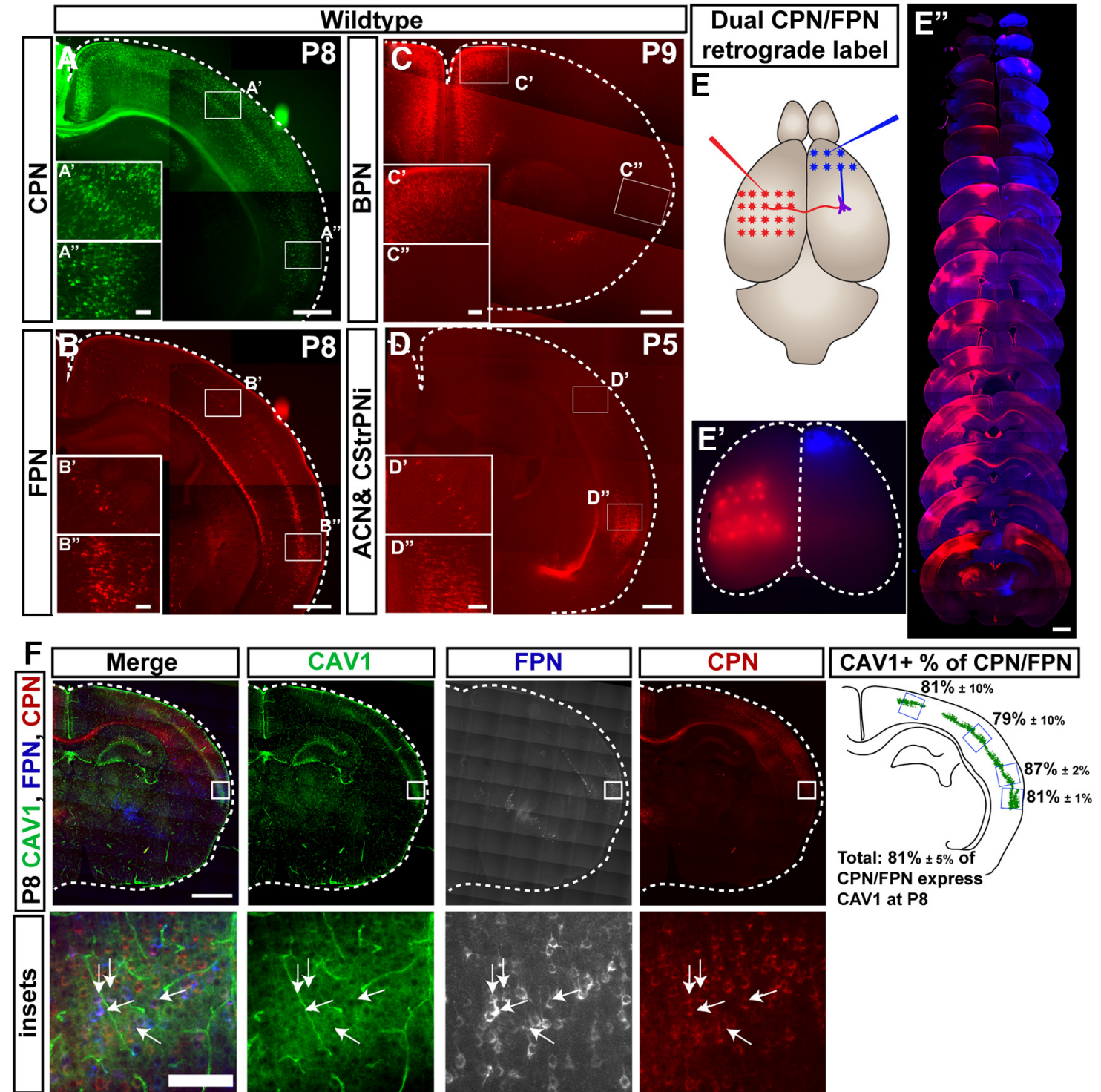

Total: $81 \% \pm 5 \%$ of

CPN/FPN express

CAV1 at P8

Figure 4. CAV1 is expressed by restricted subpopulations of neocortical neurons at P8, predominantly dual projecting CPN/FPN. Schematic representation of diverse populations of neocortical projection neurons with CPN projecting subsets, including CPN (green), CPN with a dual ipsilateral forward projection (CPN/FPN; red), CPN with a dual ipsilateral backward projection (CPN/BPN; magenta), intratelencephalic corticostriatal projection neurons (CStrPN $\mathrm{N}_{\mathrm{i}}$; blue), and anterior commissure projection neurons (ACN; yellow). $\boldsymbol{A}-\boldsymbol{D}$, Retrograde labeling was performed for CPN (A; green), FPN (B; red), BPN (C; red), and CStrPN $/ A C N(\boldsymbol{D}$; red). Both CPN and FPN are located entirely within the CAV1-expression domain, as are a subset of the mixed population of CStrPN $\mathrm{N}_{\mathrm{i}}$ and $\mathrm{ACN}$ laterally (in S2). BPN are restricted to the rostro-medial cortex, outside the CAV1-expression domain. $\boldsymbol{E}$, To identify dual-projecting CPN/FPN, we simultaneously injected $\mathrm{CTB}_{647}$ into the ipsilateral premotor cortex and $\mathrm{CTB}_{555}$ into the contralateral somatosensory cortex, as indicated by the schematic in $\boldsymbol{E}$ and wholemount image in $\boldsymbol{E}^{\prime}$. $\boldsymbol{E}^{\prime}$, FPN are isolated predominantly in Layer V, with some in VIb (subplate) in largely lateral cortical locations, with caudo-lateral S2 expansion. CPN are located in Layers II/III, V, and VI. Dual 
continued

projecting CPN/FPN are located in Layer Va in caudo-lateral cortex. $\boldsymbol{F}$, CAV1 is expressed by over $80 \%$ of dual projecting CPN/FPN. Dual projecting CPN/FPN were labeled as shown in $\boldsymbol{E}$, and the percentage of dual projecting CPN/FPN that express CAV1 was calculated for four medio-lateral regions, listed \pm SEM ( $n=4$ brains). Scale bars: $500 \mu \mathrm{m}(\boldsymbol{A}-\boldsymbol{D}), 100 \mu \mathrm{m}\left(\boldsymbol{A}^{\prime}-\boldsymbol{D}^{\prime}, \boldsymbol{A}^{\prime \prime}-\boldsymbol{D}^{\prime \prime}\right), 1 \mathrm{~mm}\left(\boldsymbol{E}^{\prime \prime}\right)$, $1 \mathrm{~mm}(\boldsymbol{F})$, and $100 \mu \mathrm{m}(\boldsymbol{F}$, inset).

CAV1 expression and localization in CPN/FPN during early neuronal maturation suggests subtype-specific function(s) during processes such as migration, neurite outgrowth, and branching. The previously known scaffolding roles of CAV1 at synapses, and its interactions with neurotransmitter receptors and Rac1 in other systems, suggest that CAV1 might influence neuronal activity through axonal/dendritic connectivity and/or function. Our results identify highly specific neocortical CAV1 expression in the dendritic compartment of dual projecting CPN/ FPN, and further identifies both that CAV1 expression is not dependent on axonal connectivity, and that correct axonal targeting of CPN/FPN is independent of CAV1.

\section{Discussion}

Identifying molecular markers and determinants of distinct subsets of CPN of the cerebral cortex will enable specific and rigorous investigation of distinct and unique subpopulations potentially critical for information integration and associative connectivity. CPN reside in cortical Layers II/III, V, and VI and all extend axons to homotopic targets in the contralateral hemisphere. Some CPN subpopulations extend second (or more) axons to distinct targets including frontal or caudal ispsilateral neocortex, or even subcortically into ipsi- or contralateral striatum (Mitchell and Macklis, 2005; Cederquist et al., 2013; Sohur et al., 2014). Increasingly specific markers and determinants will also potentially enable in-depth functional analysis of these determinants themselves through development, to gain insight into their roles in establishing precise connectivity that endows specific CPN subpopulations with critical roles in neocortical information transfer, correlation, and integration.

Here, we identify that CAV1, a lipid raft scaffolding protein enriched in CPN over CSMN (Molyneaux et al., 2009), is expressed in a restricted fashion in the developing neocortex, and is expressed by over $80 \%$ of a unique, interesting, and likely functionally special CPN subpopulation - dual projecting CPN extending axons both contralaterally and to ipsilateral frontal areas (CPN/FPN). Comparative microarray analyses have identified molecular markers and determinants of CPN subpopulations, and subsequent evaluation of these and other data reveal molecular diversity within the broad population of CPN (Molyneaux et al., 2009; Fame et al., 2016a,b). This diversity includes not only laminar and areal subpopulations, but also unique expression patterns that reflect subpopulations of CPN with distinct and sometimes multi-target axonal projections. CAV1 is a first studied example of such multi-target CPN identifiers; interestingly, it is localized to CPN cell bodies and dendrites, but is not detected in axons. The developmental temporal expression of Cav1 coincides with the intermediate time period of CPN development, including low-level expression during neuro- nal migration, and highest levels of expression from P3 to $\mathrm{P} 6$ in mice, when CPN are extending and refining axonal and dendritic processes. Together, these results suggest functions for Cav1 in postmitotic establishment of innervation and/or pruning of connections.

CAV1 has a unique, areally-restricted expression pattern within CPN of Layer Va; it is coexpressed with BHLHB5 in S1, but excluded from the LMO4-expressing M1. The reciprocal expression of LMO4 and BHLHB5 in M1 and S1, respectfully, is important for establishing these areal identities (Joshi et al., 2008b; Cederquist et al., 2013). Further, Lmo4 loss-of-function disrupts the development of dual-projecting CPN/BPN, whose cell bodies reside in the rostral motor cortex, and which send axons callosally and caudally (Cederquist et al., 2013). Thus, it is interesting to speculate that Bh/hb5 loss-of-function might similarly disrupt development of the $\mathrm{CAV} 1^{+}$dual projecting CPN/FPN.

Here, we further report that Cav1 function is not necessary for specification and early development of dual projecting CPN/FPN, investigated by precise dual retrograde labeling approaches in Cav1-null neocortex. These results are consistent with Cav1's later developmental timing of expression, and absence of subcellular localization to axons. Because these CPN/FPN projections continue to prune and establish precise connectivity until P21 (Mitchell and Macklis, 2005), future studies might employ the same or related dual labeling approaches progressively to or beyond P21 to investigate potential changes in axonal pruning that might result from potentially improper dendritic arborization, dendritic synaptogenesis, and/or axonal target-finding. If there is a change in the number of CPN/FPN in Cav1-null mice at P21, comparison between the number of CPN/FPN detected with retrograde labeling at P21 to the number detected at P21 from retrograde labeling performed at P8, for example, would be able to distinguish between axonal pruning of one or both projections, versus loss of these neurons altogether.

Because of CAV1's known interaction with neurotransmitter receptors (Lai et al., 2004; Boulware et al., 2007; Takayasu et al., 2010), dendritic spine signaling scaffolds (Gaillard et al., 2001), and synaptosome components (Bilderback et al., 1997; Bilderback et al., 1999; Braun and Madison, 2000) function(s) of CAV1 in CPN/FPN might only be elucidated optimally through electrophysiological functional analysis of these neurons lacking their endogenous Cav1 function in in vivo circuits. We find that Cav1 expression is not dependent on correct CPN connectivity, by investigating CAV1 expression in the acallosal BTBR and Fezf2 ${ }^{-1-}$ mouse lines. However, Cav1 might still be critical for CPN/FPN neuronal activity, since neuronal activity is often tightly tied to axonal and dendritic connectivity (Wang et al., 2007; Cubelos et al., 2010; Rodríguez- 

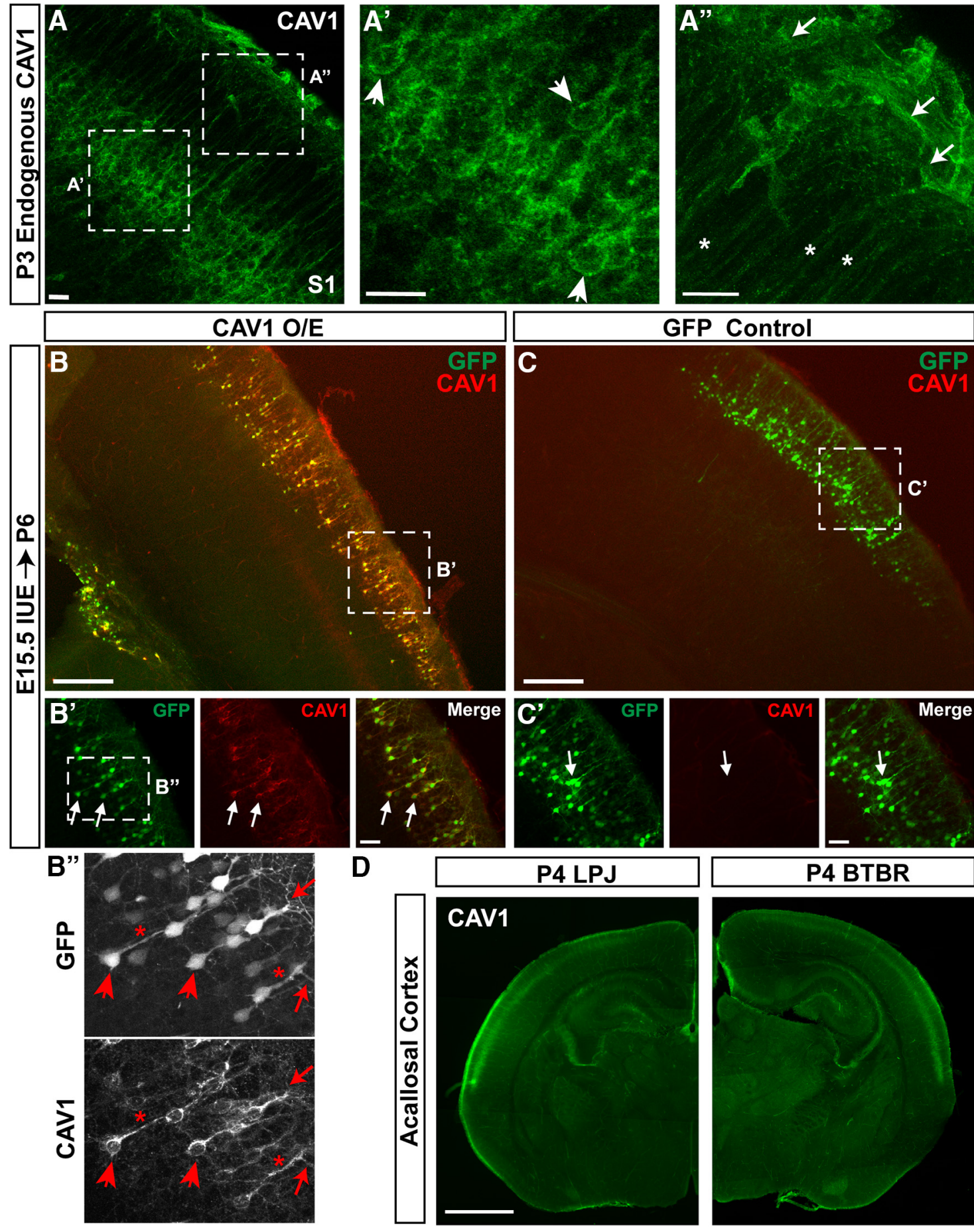

GFP Control

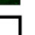



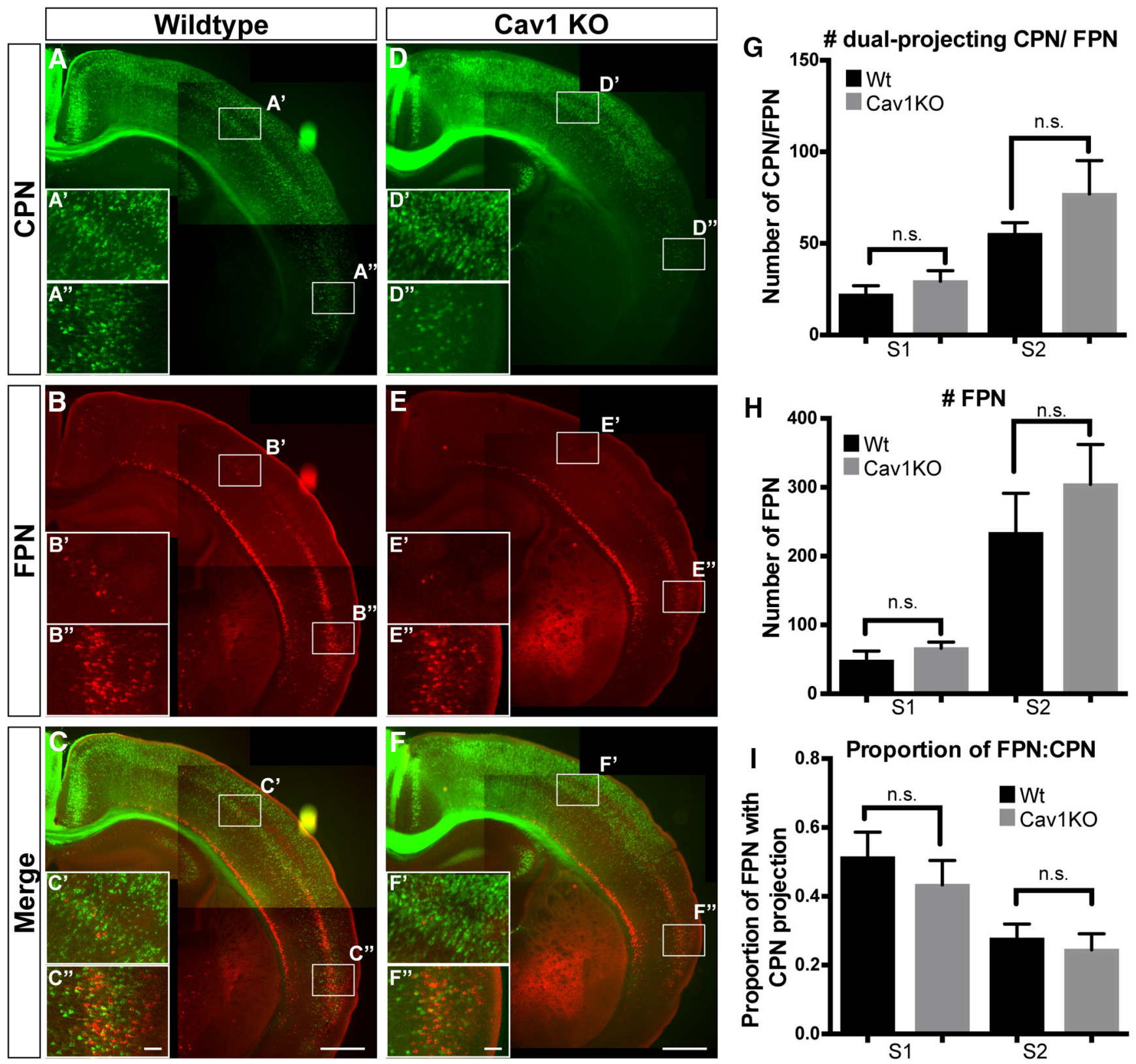

Figure 6. Loss of Cav1 function does not disrupt formation of dual projecting CPN/FPN axonal projections at P8. $\boldsymbol{A}-\boldsymbol{F}$, CPN (green) were retrogradely labeled from contralateral somatosensory cortex, and FPN (red) from ipsilateral premotor cortex in Cav1-null mice $(\boldsymbol{D}-\boldsymbol{F} ; \boldsymbol{n}=5)$ and WT littermates $(\boldsymbol{A}-\boldsymbol{C} ; n=5)$. $\boldsymbol{A}, \boldsymbol{D}$, CPN; $\boldsymbol{B}, \boldsymbol{E}, \mathrm{FPN}$; and $\boldsymbol{C}, \boldsymbol{F}, \mathrm{CPN} / \mathrm{FPN}$ form in the absence of Cav1 function. $\boldsymbol{G}$, $\boldsymbol{H}$, The number of dual projecting CPN/FPN $(\boldsymbol{G})$ and total FPN $(\boldsymbol{H})$ were counted for two medio-lateral regions (S1 and S2). There is no significant difference between the two genotypes ( $n=5 \mathrm{WT}$ and $n=5$ Cav1-nulls). I, The percentage of total labeled FPN that have a dual callosal projection was also calculated for two medio-lateral regions ( 1 and S2). There is no significant difference between the two genotypes ( $n=5$ WT and 5 Cav1-null). Error bars denote SEM. FPN, ipsilateral FPN. Scale bars: $500 \mu m(\boldsymbol{A}-\boldsymbol{F})$ and $100 \mu \mathrm{m}\left(\boldsymbol{A}^{\prime}-\boldsymbol{F}^{\prime}, \boldsymbol{A}^{\prime \prime}-\boldsymbol{F}^{\prime \prime}\right)$.

Tornos et al., 2016), especially establishment and maintenance. Studies examining P21 CPN/FPN axonal and dendritic morphologies with loss- or gain-of-function of Cav1 might reveal CAV1 function(s) in CPN/FPN activity.

We also identify that CAV1 is highly concentrated in cell bodies and apical dendrites of CPN/FPN. Interestingly, CAV1 is also localized to the cell bodies and dendrites of a subpopulation of pyramidal cortical neurons in primates
(Fame et al., 2016a), although older studies suggest that CPN/FPN might not be maintained in primates but, rather, might be pruned (Schwartz and Goldman-Rakic, 1982, 1984; Andersen et al., 1985; Johnson et al., 1989; Meissirel et al., 1991). Regardless of whether there are large or relatively rare primate CPN/FPN subpopulations, some unique properties of this subpopulation are likely conserved between mice and primates. Because of the identified conserved and specific subcellular localization of 
CAV1, future work might examine dendritic development and maintenance in Cav1-null CPN/FPN in comparison to WT. Together, these studies could provide important insight into the development of this unique dual projecting population of CPN that likely function in a variety of complex and critical processes, integrating cortical information between hemispheres and from primary sensorimotor areas to premotor cortices.

Future studies could investigate whether CAV1 directly interacts in CPN with a subset of previously identified CAV1 binding partners (particularly those shown to act in neuronal-relevant processes), and whether CAV1 functions in the development of defined subpopulations of $\mathrm{CPN}$ through these interactions. CAV1 is known to have a number of protein interactors from studies in other systems. One particularly compelling potential interacting protein for first analysis in CPN/FPN is Rac1, given that it has been shown in other systems to play roles in important neuronal functions relating to cytoskeletal dynamics and focal adhesion, such as neurite growth, adhesion, and migration (Beardsley et al., 2005; Kang et al., 2006; Joshi et al., 2008a). In particular, Rac1 is required for midline crossing of CPN (Chen et al., 2007; Kassai et al., 2008), and Rac1, recruited by CDKL5, can regulate neuronal migration and dendritic arborization of some CPN (Chen et al., 2010). Identification of neocortical binding partners of CAV1 could provide valuable insight into mechanisms of CPN subtype development/refinement through complex networks of discrete protein-protein interactions, with potential implications for subtypes of autism spectrum disorders (ASD) and/or schizophrenia. The emerging "cortical connectivity/synaptogenic hypothesis" of ASD suggests that such change(s) caused by Cav1 dysfunction might contribute to ASD and related behavioral phenotypes.

Interestingly, human Cav1 is located at 7q31.1, part of autism-linked locus 9 (Auts9), immediately upstream of $M E T$, which shows direct pretranscription start-site mutations associated with ASD (Campbell et al., 2006). It might be that Cav1 is also directly relevant in ASD, and might potentially contribute to some of the Auts9 linkage to the disorders, perhaps via CPN. Cav1 is also close genomically to Foxp2 in Auts9, which was initially suspected by some to underlie ASD language defects, but was later shown to not be causal of the Auts9 ASD linkage (Newbury et al., 2002). Other potential gene linkages in this locus (NRCAM and ST7) are relatively weak, indicating that the linkage must be accounted for, at least in part, by other Auts 9 genes, potentially partially by Cav1. CAV1 has also been implicated as a potential target for schizophrenia therapy due to its interaction with DISC1, and its ability to modulate DISC1 expression in neurons (Kassan et al., 2017).

The data we present here are, to our knowledge, the first identification of a potential molecular control over a unique and specialized dual projecting subpopulation of CPN, CPN/FPN. While CAV1 might likely function as a specific developmental and/or functional regulator in CPN/FPN, its specificity within this population also immediately provides a molecular marker. This will allow future studies to identify, genetically target, and/or purify this population to investigate and potentially discover additional potential upstream controls over CPN/FPN development. The defining properties of this CPN/FPN subpopulation, likely critical for "feed forward" information integration, are yet to be well understood, but analysis of Cav1 expression and function identifies and characterizes a first molecular marker and determinant of this unique associative and integrative neocortical projection neuron population.

Note Added in Proof: The first names of the first and last author were accidentally switched and incorrectly listed in the Early Release version published January 8, 2018. The author names have now been corrected.

\section{References}

Aboitiz F, Montiel J (2003) One hundred million years of interhemispheric communication: the history of the corpus callosum. Braz $\mathrm{J}$ Med Biol Res 36:409-420. Medline

Alcamo EA, Chirivella L, Dautzenberg M, Dobreva G, Fariñas I, Grosschedl R, McConnell SK (2008) Satb2 regulates callosal projection neuron identity in the developing cerebral cortex. Neuron 57:364-377. CrossRef Medline

Andersen RA, Asanuma C, Cowan WM (1985) Callosal and prefrontal associational projecting cell populations in area $7 \mathrm{~A}$ of the macaque monkey: a study using retrogradely transported fluorescent dyes. J Comp Neur 232:443-455. CrossRef Medline

Arlotta P, Molyneaux BJ, Chen J, Inoue J, Kominami R, Macklis JD (2005) Neuronal subtype-specific genes that control corticospinal motor neuron development in vivo. Neuron 45:207-221. CrossRef Medline

Azim E, Shnider SJ, Cederquist GY, Sohur US, Macklis JD (2009) Lmo4 and Clim1 progressively delineate cortical projection neuron subtypes during development. Cereb Cortex 19:i62-i69. CrossRef

Beardsley A, Fang K, Mertz H, Castranova V, Friend S, Liu J (2005) Loss of caveolin-1 polarity impedes endothelial cell polarization and directional movement. J Biol Chem 280:3541-3547. CrossRef Medline

Benavides-Piccione R, Hamzei-Sichani F, Ballesteros-Yáñez I, DeFelipe J, Yuste R (2006) Dendritic size of pyramidal neurons differs among mouse cortical regions. Cereb Cortex 16:990-1001. CrossRef Medline

Benoist M, Gaillard S, Castets F (2006) The striatin family: a new signaling platform in dendritic spines. J Physiol Paris 99:146-153.

Bilderback TR, Grigsby RJ, Dobrowsky RT (1997) Association of p75(NTR) with caveolin and localization of neurotrophin-induced sphingomyelin hydrolysis to caveolae. J Biol Chem 272:1092210927. Medline

Bilderback TR, Gazula VR, Lisanti MP, Dobrowsky RT (1999) Caveolin interacts with Trk A and p75(NTR) and regulates neurotrophin signaling pathways. J Biol Chem 274:257-263. Medline

Boulware MI, Kordasiewicz H, Mermelstein PG (2007) Caveolin proteins are essential for distinct effects of membrane estrogen receptors in neurons. J Neurosci 27:9941-9950. CrossRef Medline

Braun JE, Madison DV (2000) A novel SNAP25-caveolin complex correlates with the onset of persistent synaptic potentiation. $J$ Neurosci 20:5997-6006. Medline

Britanova O, de Juan Romero C, Cheung A, Kwan KY, Schwark M, Gyorgy A, Vogel T, Akopov S, Mitkovski M, Agoston D, Sestan N, Molnár Z, Tarabykin V (2008) Satb2 is a postmitotic determinant for upper-layer neuron specification in the neocortex. Neuron 57:378392. CrossRef Medline

Campbell DB, Sutcliffe JS, Ebert PJ, Militerni R, Bravaccio C, Trillo S, Elia M, Schneider C, Melmed R, Sacco R, Persico AM, Levitt $P$ (2006) A genetic variant that disrupts MET transcription is associated with autism. Proc Natl Acad Sci USA 103:16834-16839. CrossRef Medline 
Catapano LA, Arnold MW, Perez FA, Macklis JD (2001) Specific neurotrophic factors support the survival of cortical projection neurons at distinct stages of development. J Neurosci 21:88638872. Medline

Cederquist GY, Azim E, Shnider SJ, Padmanabhan H, Macklis JD (2013) Lmo4 establishes rostral motor cortex projection neuron subtype diversity. J Neurosci 33:6321-6332. CrossRef Medline

Chen B, Wang SS, Hattox AM, Rayburn H, Nelson SB, McConnell SK (2008) The Fezf2-Ctip2 genetic pathway regulates the fate choice of subcortical projection neurons in the developing cerebral cortex. Proc Natl Acad Sci USA 105:11382-11387. CrossRef Medline

Chen L, Liao G, Waclaw RR, Burns KA, Linquist D, Campbell K, Zheng Y, Kuan CY (2007) Rac1 controls the formation of midline commissures and the competency of tangential migration in ventral telencephalic neurons. J Neurosci 27:3884-3893. CrossRef Medline

Chen Q, Zhu YC, Yu J, Miao S, Zheng J, Xu L, Zhou Y, Li D, Zhang C, Tao J, Xiong ZQ (2010) CDKL5, a protein associated with rett syndrome, regulates neuronal morphogenesis via Rac1 signaling. J Neurosci 30:12777-12786. CrossRef Medline

Cubelos B, Sebastián-Serrano A, Beccari L, Calcagnotto ME, Cisneros E, Kim S, Dopazo A, Alvarez-Dolado M, Redondo JM, Bovolenta P, Walsh CA, Nieto M (2010) Cux1 and Cux2 regulate dendritic branching, spine morphology, and synapses of the upper layer neurons of the cortex. Neuron 66:523-535. CrossRef Medline

Fame RM, MacDonald JL, Macklis JD (2011) Development, specification, and diversity of callosal projection neurons. Trends Neurosci 34:41-50. CrossRef Medline

Fame RM, Dehay C, Kennedy H, Macklis JD (2016a) Subtypespecific genes that characterize subpopulations of callosal projection neurons in mouse identify molecularly homologous populations in macaque cortex. Cereb Cortex 27:1817-1830.

Fame RM, MacDonald JL, Dunwoodie SL, Takahashi E, Macklis JD (2016b) Cited2 regulates neocortical layer II/III generation and somatosensory callosal projection neuron development and connectivity. J Neurosci 36:6403-6419.

Gaillard S, Bartoli M, Castets F, Monaghan AP (2001) Striatin, a calmodulin-dependent scaffolding protein, directly binds caveolin-1. FEBS Lett 508:49-52.

Greig LC, Woodworth MB, Galazo MJ, Padmanabhan H, Macklis JD (2013) Molecular logic of neocortical projection neuron specification, development and diversity. Nat Rev Neurosci 14:755-769. CrossRef

Head BP, Insel PA (2007) Do caveolins regulate cells by actions outside of caveolae? Trends Cell Biol 17:51-57. CrossRef Medline

Hirata T, Suda Y, Nakao K, Narimatsu M, Hirano T, Hibi M (2004) Zinc finger gene fez-like functions in the formation of subplate neurons and thalamocortical axons. Dev Dyn 230:546-556. CrossRef Medline

Huang Z, Kawase-Koga Y, Zhang S, Visvader J, Toth M, Walsh CA, Sun $T$ (2009) Transcription factor Lmo4 defines the shape of functional areas in developing cortices and regulates sensorimotor control. Dev Biol 327:132-142. CrossRef Medline

Ivy GO, Killackey HP (1981) The ontogeny of the distribution of callosal projection neurons in the rat parietal cortex. J Comp Neur 195:367-389. CrossRef Medline

Johnson PB, Angelucci A, Ziparo RM, Minciacchi D, Bentivoglio M, Caminiti R (1989) Segregation and overlap of callosal and association neurons in frontal and parietal cortices of primates: a spectral and coherency analysis. J Neurosci 9:2313-2326. Medline

Joshi B, Strugnell SS, Goetz JG, Kojic LD, Cox ME, Griffith OL, Chan SK, Jones SJ, Leung SP, Masoudi H, Leung S, Wiseman SM, Nabi IR (2008a) Phosphorylated caveolin-1 regulates Rho/ROCKdependent focal adhesion dynamics and tumor cell migration and invasion. Cancer Res 68:8210-8220.

Joshi PS, Molyneaux BJ, Feng L, Xie X, Macklis JD, Gan L (2008b) Bhlhb5 regulates the postmitotic acquisition of area identities in layers II-V of the developing neocortex. Neuron 60:258-272. CrossRef Medline
Kachi S, Yamazaki A, Usukura J (2001) Localization of caveolin-1 in photoreceptor synaptic ribbons. Invest Ophthalmol Vis Sci 42: 850-852. Medline

Kang MJ, Seo JS, Park WY (2006) Caveolin-1 inhibits neurite growth by blocking Rac1/Cdc42 and p21-activated kinase 1 interactions. Neuroreport 17:823-827. CrossRef Medline

Kassai H, Terashima T, Fukaya M, Nakao K, Sakahara M, Watanabe M, Aiba A (2008) Rac1 in cortical projection neurons is selectively required for midline crossing of commissural axonal formation. Eur $J$ Neurosci 28:257-267. CrossRef Medline

Kassan A, Egawa J, Zhang Z, Almenar-Queralt A, Nguyen QM, Lajevardi Y, Kim K, Posadas E, Jeste DV, Roth DM, Patel PM, Patel $\mathrm{HH}$, Head BP (2017) Caveolin-1 regulation of disrupted-inschizophrenia-1 as a potential therapeutic target for schizophrenia. J Neurophysiol 117:436-444. CrossRef Medline

Lai H, Boone T, Yang G, Smith C, Kiss S, Thompson TC, Somogyi GT (2004) Loss of caveolin-1 expression is associated with disruption of muscarinic cholinergic activities in the urinary bladder. Neurochem Int 45:1185-1193.

Li Y, Luo J, Lau WM, Zheng G, Fu S, Wang TT, Zeng HP, So KF, Chung SK, Tong Y, Liu K, Shen J (2011) Caveolin-1 plays a crucial role in inhibiting neuronal differentiation of neural stem/progenitor cells via VEGF signaling-dependent pathway. PLoS One 6:e22901. CrossRef

MacDonald JL, Fame RM, Azim E, Shnider SJ, Molyneaux BJ, Arlotta P, Macklis JD (2013) Specification of cortical projection neurons: transcriptional mechanisms. In: Comprehensive developmental neuroscience: patterning and cell type specification in the developing CNS and PNS. (Rubenstein JLR, Rakic P, ed), pp 475-502. New York: Elsevier.

Maggi D, Biedi C, Segat D, Barbero D, Panetta D, Cordera R (2002) IGF-I induces caveolin 1 tyrosine phosphorylation and translocation in the lipid rafts. Biochem Biophys Res Commun 295:10851089.

Marin R, Díaz M, Alonso R, Sanz A, Arévalo MA, Garcia-Segura LM (2009) Role of estrogen receptor $\alpha$ in membrane-initiated signaling in neural cells: interaction with IGF-1 receptor. J Steroid Biochem Mol Biol 114:2-7. CrossRef Medline

Meissirel C, Dehay C, Berland M, Kennedy H (1991) Segregation of callosal and association pathways during development in the visual cortex of the primate. J Neurosci 11:3297-3316. Medline

Mitchell BD, Macklis JD (2005) Large-scale maintenance of dual projections by callosal and frontal cortical projection neurons in adult mice. J Comp Neur 482:17-32. CrossRef Medline

Molyneaux BJ, Arlotta P, Hirata T, Hibi M, Macklis JD (2005) Fezl is required for the birth and specification of corticospinal motor neurons. Neuron 47:817-831. CrossRef Medline

Molyneaux BJ, Arlotta P, Fame RM, MacDonald JL, MacQuarrie KL, Macklis JD (2009) Novel subtype-specific genes identify distinct subpopulations of callosal projection neurons. J Neurosci 29: 12343-12354. CrossRef

Newbury DF, Bonora E, Lamb JA, Fisher SE, Lai CS, Baird G, Jannoun L, Slonims V, Stott CM, Merricks MJ, Bolton PF, Bailey AJ, Monaco AP; International Molecular Genetic Study of Autism Consortium (2002) FOXP2 is not a major susceptibility gene for autism or specific language impairment. Am J Hum Genet 70: 1318-1327. CrossRef Medline

Otsuka T, Kawaguchi Y (2011) Cell diversity and connection specificity between callosal projection neurons in the frontal cortex. $\mathrm{J}$ Neurosci 31:3862-3870. CrossRef Medline

Ozdinler PH, Macklis JD (2006) IGF-I specifically enhances axon outgrowth of corticospinal motor neurons. Nat Neurosci 9:13711381. CrossRef Medline

Polleux F, Dehay C, Goffinet A, Kennedy H (2001) Pre- and postmitotic events contribute to the progressive acquisition of areaspecific connectional fate in the neocortex. Cereb Cortex 11: 1027-1039. Medline

Razani B, Engelman JA, Wang XB, Schubert W, Zhang XL, Marks CB, Macaluso F, Russell RG, Li M, Pestell RG, Di Vizio D, Hou H, Kneitz B, Lagaud G, Christ GJ, Edelmann W, Lisanti MP (2001) 
Caveolin-1 null mice are viable but show evidence of hyperproliferative and vascular abnormalities. J Biol Chem 276:38121-38138. CrossRef Medline

Rodríguez-Tornos FM, Briz CG, Weiss LA, Sebastián-Serrano A, Ares S, Navarrete M, Frangeul L, Galazo M, Jabaudon D, Esteban JA, Nieto M (2016) Cux1 enables interhemispheric connections of layer II/III neurons by regulating Kv1-dependent firing. Neuron 89:494-506. CrossRef Medline

Saito T (2006) In vivo electroporation in the embryonic mouse central nervous system. Nat Protoc 1:1552-1558. CrossRef Medline

Saito T, Nakatsuji N (2001) Efficient gene transfer into the embryonic mouse brain using in vivo electroporation. Dev Biol 240:237-246. CrossRef Medline

Schubert W, Frank PG, Woodman SE, Hyogo H, Cohen DE, Chow C-W, Lisanti MP (2002) Microvascular hyperpermeability in caveolin-1 (-/-) knock-out mice. Treatment with a specific nitricoxide synthase inhibitor, L-NAME, restores normal microvascular permeability in Cav-1 null mice. J Biol Chem 277:40091-40098. CrossRef Medline

Schwartz ML, Goldman-Rakic PS (1982) Single cortical neurones have axon collaterals to ipsilateral and contralateral cortex in fetal and adult primates. Nature 299:154-155. Medline

Schwartz ML, Goldman-Rakic PS (1984) Callosal and intrahemispheric connectivity of the prefrontal association cortex in rhesus monkey: relation between intraparietal and principal sulcal cortex. J Comp Neur 226:403-420. CrossRef Medline

Silver J, Lorenz SE, Wahlsten D, Coughlin J (1982) Axonal guidance during development of the great cerebral commissures: descriptive and experimental studies, in vivo, on the role of preformed glial pathways. J Comp Neur 210:10-29. CrossRef Medline
Sohur US, Padmanabhan HK, Kotchetkov IS, Menezes JR, Macklis JD (2014) Anatomic and molecular development of corticostriatal projection neurons in mice. Cereb Cortex 24:293-303. CrossRef Medline

Takayasu Y, Takeuchi K, Kumari R, Bennett MV, Zukin RS, Francesconi A (2010) Caveolin-1 knockout mice exhibit impaired induction of mGluR-dependent long-term depression at CA3-CA1 synapses. Proc Natl Acad Sci USA 107:21778-21783. CrossRef Medline

Trushina E, Du Charme J, Parisi J, Mcmurray C (2006) Neurological abnormalities in caveolin-1 knock out mice. Behav Brain Res 172:24-32. CrossRef

Vega CJ, Peterson DA (2005) Stem cell proliferative history in tissue revealed by temporal halogenated thymidine analog discrimination. Nat Methods 2:167-169. CrossRef Medline

Wahlsten D, Metten P, Crabbe JC (2003) Survey of 21 inbred mouse strains in two laboratories reveals that BTBR $\mathrm{T} /+\mathrm{tf} / \mathrm{tf}$ has severely reduced hippocampal commissure and absent corpus callosum. Brain Res 971:47-54. CrossRef

Wang C, Zhang L, Zhou Y, Zhou J, Yang X, Duan S, Xiong Z, Ding Y (2007) Activity-dependent development of callosal projections in the somatosensory cortex. J Neurosci 27:11334-11342. CrossRef Medline

Woodworth MB, Greig LC, Liu KX, Ippolito GC, Tucker HO, Macklis JD (2016) Ctip1 regulates the balance between specification of distinct projection neuron subtypes in deep cortical layers. Cell Rep 15:999-1012. CrossRef Medline

Zhao YL, Song JN, Zhang M (2014) Role of caveolin-1 in the biology of the blood-brain barrier. Rev Neurosci 25:247-254. CrossRef Medline 